\title{
As rochas vulcânicas mesozóicas ácidas da Bacia do Paraná: litoestratigrafia e considerações geoquímico-estratigráficas
}

\author{
Antonio José Ranalli Nardy ${ }^{1}$, Fábio Braz Machado ${ }^{2,3}$ \& Marcos Aurélio Farias de Oliveira ${ }^{4}$
}

\begin{abstract}
Resumo As rochas vulcânicas ácidas mesozóicas da Bacia do Paraná recobrem uma área de $64.000 \mathrm{~km}^{2} \mathrm{e}$ representam 2,5\% do volume total da Formação Serra Geral. São caracterizadas por dois grupos petrograficamente distintos denominados de Palmas (afíricos) e Chapecó (porfiríticos), sendo o primeiro grupo majoritário, representando $2 \%$ do volume total, enquanto o segundo apenas $0,5 \%$. É possível observar as relações de contato entre eles apenas em algumas regiões no sul do Estado do Paraná, sendo que o tipo Chapecó sobrepõe o Palmas. Do ponto de vista litogeoquímico, as rochas do tipo Chapecó são mais enriquecidas em Ba, Nb, La, $\mathrm{Ce}, \mathrm{Zr}$, P. Nd, Y, Yb, Lu e K e empobrecidas em Rb, Th e U em comparação com as do tipo Palmas. O forte enriquecimento de alguns elementos traços (e.g. $\mathrm{Nb}=2,58)$ aponta para fontes magmáticas distintas, e de processos de contaminação crustal evidenciados pelas relações $\mathrm{Rb} / \mathrm{Ba}$ (de 0,27 a 0,31 para as do tipo Palmas e de 0,09 a 0,11 para as do tipo Chapecó). Esses dados permitem reconhecer cinco subgrupos distintos de rochas do tipo Palmas, denominados de Santa Maria, Caxias do Sul, Anita Garibaldi (Peate el al., 1997), Clevelândia e Jacuí e outros três subgrupos de rochas do tipo Chapecó, denominados de Ourinhos, Guarapuava (Peate el al., 1997) e Tamarana, que parecem estar fortemente condicionadas às suas distribuições espaciais. As diferentes seções colunares dessas rochas parecem indicar que os vários tipos e subtipos de rochas vulcânicas ácidas correspondem a diferentes magmas-tipo e a unidades estratigráficas diacrônicas.
\end{abstract}

Palavras-Chave: Vulcanismo Mesozóico, Formação Serra Geral, Rochas Vulcânicas Ácidas.

\begin{abstract}
The mesozoic acidic volcanic rocks of Paraná Basin: lithostratigraphy and geochemical stratigraphy aspects. The mesozoic acidic volcanics of Paraná Basin covers an area of $64,000 \mathrm{~km}^{2}$ or $2.5 \%$ of the total volume of Serra Geral Formation. Two main types are recognized and are named Palmas (aphyric rocks) and Chapecó (porphyritic rocks). The Palmas type (2\% of total volume) dominate over the Chapecó $(0.5 \%$ vol.) one. In the Paraná State, it is possible to found the Chapecó overlaying the Palmas volcanic rocks. The geochemical data shows that Chapecó volcanics have distinctly higher $\mathrm{Ba}, \mathrm{Nb}, \mathrm{La}, \mathrm{Ce}, \mathrm{Zr}, \mathrm{P} . \mathrm{Nd}, \mathrm{Y}, \mathrm{Yb}$, $\mathrm{Lu}$ e $\mathrm{K}$ and lower concentrations of $\mathrm{Rb}$, Th and $\mathrm{U}$ relative to Palmas rocks. The Nb concentration in Chapecó rocks is 2.58 times higher than Palmas leading to the suggestion that the magmatic sources of Palmas and Chapecó rocks are different. The $\mathrm{Rb} / \mathrm{Ba}$ of Chapecó $(0,09-0,11)$ and Palmas rocks $(0,27-0,31)$ indicates that crustal assimilation process is very important to explain the origin of these rocks, mainly the Palmas type. The geochemical data allow us to recognize five different types of Palmas volcanic rocks named Santa Maria, Caxias do Sul, Anita Garibaldi (Peate el al., 1997), Clevelândia and Jacuí, and three different types of Chapecó volcanics, named Ourinhos, Tamarana (Peate el al., 1997) e Guarapuava, which are strongly correlated with their regional distribution in Paraná Basin, and appear to have evolved from different magma-types. The regional and temporal relationships of the different acidic volcanic rocks point to diacronous stratigraphic units.
\end{abstract}

Keywords: Mesozoic Volcanism, Serra Geral Formation, Acidic Volcanic Rocks.

INTRODUÇÃo Durante o Mesozóico, o supercontinente Gondwana foi palco de intensa atividade magmática, resultando extensos derrames em certas regiões desse continente. Posteriormente, por meio de processos distensivos da litosfera deu-se a separação continental, com o aparecimento de novas bacias oceânicas. Dentre essas regiões destacam-se as Províncias Magmáticas do Karoo (no sul do continente africano) e a de Ferrar (compreendendo parte dos continentes da
Antártica, Tasmânia, e Austrália), cujos magmatismos jurássicos precederam a formação do Oceano Índico. Já as províncias cretácicas do Paraná (América do Sul) e do Etendeka (África) antecederam a formação da porção sul do Oceano Atlântico.

Todas essas províncias continentais são consideradas como grandes regiões magmáticas, ou LIPs (cf. Coffin \& Eldholm, 2001), possuindo certas características em comum, como a predominância de lavas de na-

1 - Instituto de Geociências e Ciências Exatas, UNESP, Rio Claro (SP), Brasil. E-mail: nardy@rc.unesp.br

2 - Programa de Pós-Graduação em Geologia Regional, Instituto de Geociências e Ciências Exatas, UNESP, Rio Claro (SP), Brasil.

E-mail: fabiobm@rc.unesp.br

3 - Centro Universitário Salesiano de São Paulo, UNISAL, Americana (SP), Brasil.

4 - Instituto de Geociências e Ciências Exatas, UNESP, Rio Claro (SP), Brasil. E-mail: maurelio@rc.unesp.br 
tureza toleítica distribuídas por superfícies superiores a $0,1 \mathrm{Mkm}^{2}$ e acumuladas em volumes de pelo menos 1 $\mathrm{Mkm}^{3}$, extravasados em períodos de tempo relativamente curtos, algo em torno de alguns poucos milhões de anos. Rochas de composição ácida-intermediária na forma de lavas ou como intrusivas estão também presentes, normalmente associadas ao início ou ao final do magmatismo (Coffin \& Eldholm, 2001; Ernst el al., 2005).

Nesse contexto, a Província do Paraná-Etendeka é a mais expressiva delas, sendo constituída por um volume de magma da ordem de $1 \mathrm{Mkm}^{3}$. Dessa província parecem também fazer parte os derrames associados às bacias de Cuanza e Namibe, localizadas na costa oeste de Angola (Piccirillo el al., 1990; Alberti el al., 1992). Entretanto, o imenso volume de magma produzido nesse período na província não se distribuiu de forma uniforme entre os dois continentes. No africano, em especial na região do Etendeka, as lavas recobriram uma área aproximada de $0,78 \mathrm{Mkm}^{2}$, além de acumuladas em uma pilha de até $1 \mathrm{~km}$ de espessura (Peate, 1997; Marsh el al., 2001). No continente sul-americano, na Província Magmática do Paraná, estima-se estarem 95\% de todo o volume de magma produzido (Milner el al., 1995), estendido por cerca de $1,2 \mathrm{Mkm}^{2}$, o que equivale a 75\% da superfície da Bacia do Paraná, em seqüências de até $1,7 \mathrm{~km}$ de espessura, resultando um volume da ordem de $0,8 \mathrm{Mkm}^{3}$ de lavas (Melfi el al., 1988). Devese ainda considerar que esse imenso volume de material vulcânico é remanescente de um extenso processo de erosão que atingiu a Plataforma Sul-Americana e que, segundo Gallagher el al. (1994), o teria reduzido em pelo menos uma ordem de grandeza. Desse volume total de lavas toleíticas registrado, cerca de $90 \%$ são de basalto e o restante de natureza félsica, andesitos e riolitos (Piccirillo et. al., 1988). Ao extenso campo de lavas se associa intensa atividade intrusiva discordante, como as relativas aos enxames de diques do Arco de Ponta Grossa, de direção preferencial NW-SE, e da Serra do Mar, dispostos paralelamente à costa brasileira e encontrados principalmente nos estados de São Paulo e Rio de Janeiro. Associam-se também potentes sills de diabásio encaixados preferencialmente nos sedimentos paleozóicos da Bacia do Paraná, comuns nos estados de São Paulo e Paraná.

Porém, a porção mais significativa da província é a dos derrames constituindo a Formação Serra Geral, que cobre praticamente toda a região meridional do Brasil, as áreas oriental do Paraguai e ocidental do Uruguai (Formação Arapey), e a do norte da Argentina (Membro Posadas da Formação Curuzú Cuatiá).

As idades das rochas vulcânicas da província, obtidas por meio de datações ${ }^{40} \mathrm{Ar} /{ }^{39} \mathrm{Ar}$, revelam que o pico de atividade ígnea ocorreu num curto espaço de tempo, entre 133 e $130 \mathrm{Ma}$ (Renne el al., 1992a, 1996a, b; Turner el al., 1994; Ernesto el al., 1999, 2002; Mincato el al., 2003). Essas idades são coerentes com os dados paleomagnéticos relativos à freqüência de reversões e de variações seculares do campo geomagnético, produzidos a partir de seqüências de lavas das regiões central e sul da Bacia do Paraná que apresentam até 1 $\mathrm{km}$ de espessura, acumuladas em um intervalo de até 1 Ma (Renne el al. 1992a; Ernesto el al., 1999).

Além disso, as idades das rochas vulcânicas na porção sul da Bacia do Paraná situam-se entre 131,4 1,6 e 132,9 Ma (Renne el al., 1992a) enquanto que as das regiões norte e central entre $129,9 \pm 0,1 \mathrm{Ma} \mathrm{e}$ 131,9 $\pm 0,9 \mathrm{Ma}$ (Renne el al., 1992b). Ainda, as idades observadas na porção norte da Bacia do Paraná são praticamente as mesmas das lavas do Etendeka $(131,7 \pm 0,7$ Ma e 132,3 $\pm 0,7$ Ma; Renne el al., 1996b) e da Bacia de

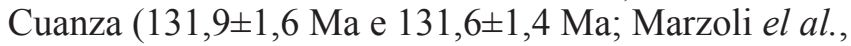
1999). Assim sendo, parece que o vulcanismo que afetou a Província Magmática do Paraná-Etendeka migrou de Sul para Norte. Esta hipótese também é corroborada pelas idades determinadas em rochas intrusivas do enxame de diques do Arco de Ponta Grossa (129-131 Ma; Turner el al., 1994 e Renne el al. 1996a), da Serra do Mar (131 Ma, Renne el al., 1996b), dos diques costeiros de Florianópolis (129-119 Ma, Deckart el al., 1998) e também das bacias marginais de Campos e Santos, com valores da ordem de $124 \mathrm{Ma}$ (Mizusaki el al., 1992). Ainda, as curvas de deriva polar obtidas a partir de dados paleomagnéticos das rochas intrusivas e extrusivas da Província Magmática do Paraná (Ernesto el al., 1999) apontam também para esse sentido de migração do vulcanismo na província.

De modo geral, a observação macroscópica das rochas vulcânicas da Formação Serra Geral permite individualizar três tipos petrográficos principais, facilmente reconhecíveis. O primeiro deles, majoritário, corresponde ao dos basaltos, que exibem predominantemente textura intergranular e suas variações (intersertal, hialofítica, etc). Os outros dois são representados por rochas de natureza ácida, denominadas de Palmas e Chapecó, sendo, respectivamente, as primeiras maciças e afíricas, e as segundas porfiríticas. A facilidade de reconhecimento a olho nu permitiu a sua cartografia com a definição de dois novos membros associados à Formação Geral, caracterizados pela presença dessas rochas-tipo intercaladas aos basaltos.

Essas rochas de natureza ácida não são exclusivas da Província Magmática do Paraná, mas ocorrem também em parte da porção oeste do continente africano. De maneira geral, as do tipo Chapecó são reconhecidass nas bacias do Cuanza e Namibe, na porção sul de Angola, além de um pouco mais ao sul, já na Província Magmática do Etendeka, na Namíbia, na região de Sarusas. Por sua vez, as ácidas do tipo Palmas estão presentes mais ao sul da província, na região de Tafelberg (Fig. 1).

Embora o volume do vulcanismo observado no continente africano, cerca de $0,5 \%$, no Etendeka, seja pouco representativo em relação ao da Formação Serra Geral as rochas de natureza ácida chegam a constituir até 50\% do total (Marsh el al., 2001).

Além disso, essas vulcânicas não estão distribuídas de forma aleatória pela Província do Paraná-Etendeka, mas, sim, concentradas próximas às atuais linhas costeiras dos continentes sul-americano e africano, a indicar que geneticamente estiveram associadas de algum 


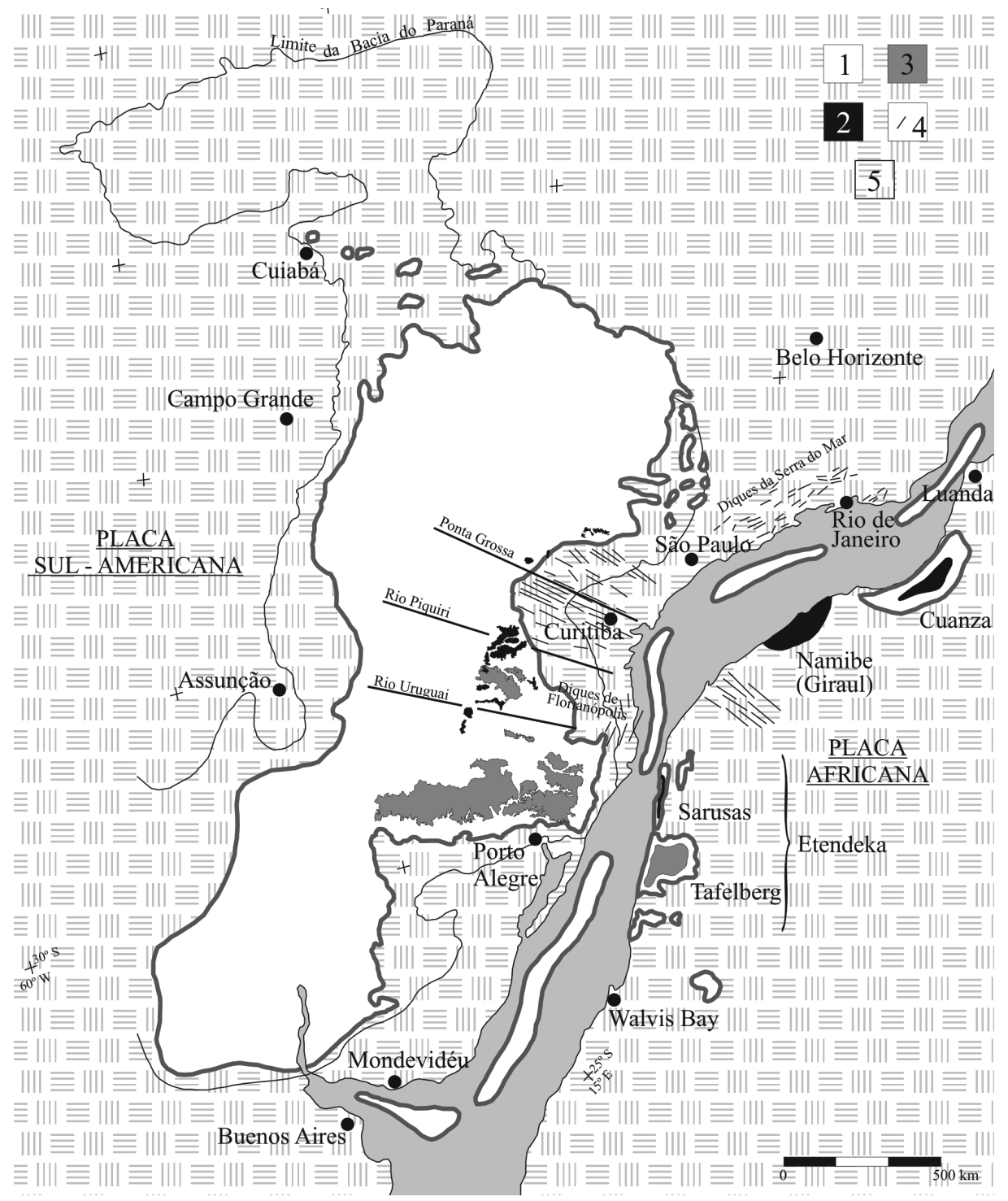

Figura 1 - Mapa pré-drift da Província Magmática do Paraná-Etendeka. Legenda: 1. basaltos, 2. vulcânicas ácidas do tipo Chapecó, 3. vulcânicas ácidas do tipo Palmas, 4. diques, 5. área adjacente. Modificado de Milner el al. (1995), Stewart el al. (1996), Peate (1997) e Nardy (2002).

modo à separação do Gondwana. Assim, o seu estudo mais detalhado remete-nos ao conhecimento dos últimos pulsos magmáticos registrados na Província Magmática do Paraná antes do processo de ruptura continental que levou à formação da África e da América do Sul.

Este trabalho tem como objetivo apresentar novos dados sobre a litoestratigrafia das vulcânicas ácidas dos tipos Palmas e Chapecó da Formação Serra Geral, suas características litogeoquímicas e aspectos geoquímico-estratigráficos, de forma a contribuir para um melhor entendimento sobre origem e evolução dessas rochas na Bacia do Paraná.

LITOESTRATIGRAFIA As rochas vulcânicas ácidas do tipo Palmas (ATP) são caracterizadas pela coloração cinza clara, às vezes adquirindo tonalidade vermelho-acastanhada, natureza afírica, textura hipo a holohialina com marcante aspecto sal-e-pimenta. Sua mineralogia essencial é de microfenocristais (granulação inferior a $0,2 \mathrm{~mm}$ ) de plagioclásio (labradorita), que chega a constituir até $16 \%$ do volume total da rocha, $11 \%$ de augita, $3 \%$ de pigeonita, $5 \%$ de magnetita e menos de $1 \%$ de apatita. Esses cristais exibem muitas vezes estruturas de resfriamento rápido, desenvolvendo formas esqueléticas, aciculares, ocas ou terminações em forma de cúspide. A matriz é composta por material semivítreo, que atinge em média $63 \%$ do volume da rocha, de coloração castanha escura, levemente birrefringente, caracterizado pelo intenso intercrescimento de microlitos de quartzo e feldspato alcalino na forma de textura granofírica, que envolve por completo as fases cristalinas. Quando holohialinas (pichestones), essas rochas mostram coloração negra e fratura conchoidal proeminente. Entretanto, devido à sua natureza amorfa, 
alteram-se com muita facilidade e, assim, na maioria dos afloramentos, encontram-se totalmente intemperizadas, com coloração acastanhada, lembrando depósitos de natureza sedimentar, salpicados de vesículas e amígdalas com até $10 \mathrm{~mm}$ de comprimento, normalmente preenchidas por quartzo.

As rochas vulcânicas ácidas do tipo Chapecó (ATC) são porfiríticas, com cerca de $24 \%$ de fenocristais de plagioclásio com até $2 \mathrm{~cm}$ de comprimento, imersos em matriz afanítica de coloração cinza clara quando fresca e acastanhada quando alterada. A mineralogia consiste em fenocristais euhedrais de andesina imersos em matriz constituída fundamentalmente por $4,5 \%$ de augita, $2,2 \%$ de pigeonita, $3,7 \%$ de magnetita e $1,7 \%$ de apatita (valores médios) envoltos por uma trama de quartzo e feldspato alcalino em arranjo felsítico, localmente granofírico, imprimindo à rocha textura vitrofírica.

Dos quase cem perfis estudados, observouse que os corpos de natureza ácida são tabulares e de grande extensão lateral, da ordem de algumas dezenas de quilômetros. Dados paleomagnéticos de Pacca \& Ernesto (1982) e geoquímicos Nardy (1996) sugerem extensões da ordem de $30 \mathrm{~km}$. Verticalmente, verificase a presença de estruturas e texturas que permitem definir três domínios principais. O inferior, ou basal, é caracterizado por uma zona de atrito entre o substrato, de basalto, e o fluxo magmático de composição ácida. Dessa interação resultam brechas epiclásticas, constituídas por fragmentos angulosos de até $20 \mathrm{~cm}$ de comprimento de basalto, normalmente vesicular, soldados por uma matriz vítrea de composição ácida. É abundante a presença de minerais secundários e de preenchimento, como calcita, zeólitas, quartzo, limonita, etc. Esse domínio é pouco expressivo frente à espessura total das seções. Ele chega a apresentar de 1 até $5 \mathrm{~m}$, embora na maioria dos perfis analisados esteja ausente, sugerindo que o atrito com o substrato foi pequeno. $\mathrm{O}$ domínio intermediário, ou principal, é mais homogêneo, correspondendo a uma região de resfriamento e compactação do corpo magmático sem demonstrar evidências acentuadas de fluxo. É caracterizado predominantemente por rochas de natureza maciça, embora vesículas e amígdalas levemente achatadas, com alguns milímetros de comprimento, estejam espalhadas ao longo de toda a seção. Em geral, não ultrapassam 1\% do volume total da rocha, mas tornam-se mais abundantes e maiores, atingindo até $10 \mathrm{~mm}$ de comprimento, nas proximidades do topo da seqüência. O diaclasamento é também uma estrutura característica desse domínio, sendo representado por juntas de atitude vertical, contínuas, com espaçamento horizontal entre 1 e $2 \mathrm{~m}$. Localmente, ocorre também um persistente bandamento ígneo, onde bandas de coloração branca alternam-se a outras de coloração escura. As claras têm cerca de $2 \mathrm{~cm}$ de espessura, composição quartzo-feldspática e mostram maior grau de cristalinidade em comparação com as bandas escuras, que, por sua vez, exibem coloração cinza escuro e natureza hipohialina. Esse bandamento, via de regra, apresenta atitude horizontal e se caracteriza pela grande continuidade lateral, persistindo por vários qui- lômetros de extensão, especialmente nos afloramentos de rochas do tipo Chapecó. A relação de contato entre as duas bandas é difusa, observando-se fenocristais de plagioclásio não orientados compartilhados entre ambas e, portanto, aparentando não terem sido diretamente afetados pelo fluxo, mas provavelmente por diferenças no grau de compactação e concentração de voláteis. Muito possivelmente essa estrutura tenha se desenvolvido após o fenômeno de escoamento do magma na superfície, durante o processo de resfriamento.

O domínio superior, ou de topo, é o que apresenta maior diversidade de estruturas, todas ligadas a processos de fluxo. A sua porção inferior caracteriza-se pela presença de diaclasamento plano-paralelo cerrado, onde lajes com espessuras variando de 10 a $20 \mathrm{~cm}$ formam uma pilha de até $10 \mathrm{~m}$. Esse tipo de estrutura é também denominado de acamamento ígneo, tendo em vista ser produzido pela movimentação de um líquido viscoso sobre uma paleo-superfície praticamente lisa e horizontal. Porém, à medida que se aproxima do topo do domínio as estruturas assumem um padrão ondulado, que configura em escala de afloramento anticlinais e sinclinais, podendo inclusive apresentar atitude vertical. Embora seja uma estrutura comum para ambas as seqüências de rochas ácidas, ela é mais freqüente e proeminente naquelas do tipo Palmas. Ressalta-se, porém, que nem todas as amostras desse domínio, analisadas sob microscopia de luz polarizada, exibem textura que denuncie o fluxo da lava na superfície, em especial a pilotaxítica (cristais orientados por fluxo), o que sugere que o mesmo possa ter ocorrido em curto espaço de tempo e a temperaturas elevadas, acima de $1000^{\circ}$ $\mathrm{C}$, conforme indicam os resultados geotermométricos das principais fases minerais (piroxênios, plagioclásio e magnetita) (Bellieni el al., 1986; Garland el al., 1995). A cristalização parece ter sido ainda rápida, pois essas rochas apresentam textura hipohialina (a concentração de matriz vítrea pode ser superior a $75 \%$ do volume total da rocha) e os microfenocristais presentes mostram, em sua maioria, interiores ocos, terminações em forma de cúspide ou então hábito acicular.

Entretanto, outras estruturas típicas de fluxo estão presentes e são bastante abundantes nesse domínio. Uma delas é o lineamento mineral, onde microcristais de feldspato e quartzo intercrescidos formam filetes de coloração clara, com alguns milímetros de espessura, dobrados em um padrão complexo, sugerindo forte influência do fluxo magmático imposto às rochas nas etapas finais de cristalização.

É ainda nessa região que se reconhece a presença de uma zona de brechas autoclásticas, fortemente marcadas por estruturas de fluxo e com até $2 \mathrm{~m}$ de espessura, possivelmente geradas pelo movimento de uma massa magmática viscosa que engloba parte do material já extravasado à superfície, total ou parcialmente solidificado.

Por fim, nas seqüências de rochas ácidas do tipo Palmas, ainda no domínio superior, é comum observar corpos lenticulares com até $10 \mathrm{~m}$ de espessura de rochas holohialinas, de coloração negra, fratura conchoidal e 
brilho de piche (pichestones), intercaladas às variedades hipohialinas (Fig. 2).

As rochas vulcânicas ácidas da Formação Serra Geral ocorrem associadas a extensos platôs, em altos topográficos, com pequena cobertura vegetal, que se destacam nas imagens de satélite, em especial nas infravermelhas, apresentando coloração cinza-esbranquiçada. Já nas imagens de radar, elas estão representadas por superfícies lisas com baixa densidade de elementos texturais.

Baseado nessas características, Nardy el al. (2002), com o objetivo de cartografar as rochas ácidas da Bacia do Paraná, propuseram a incorporação de duas novas unidades litoestratigráficas à Formação Serra Geral, denominadas de Membros Palmas e Chapecó, e caracterizadas pela presença das rochas homônimas associadas a intercalações de basaltos e andesitos. O mapa litoestratigráfico obtido é mostrado na figura 3 , de onde se destaca que as unidades ácidas cobrem 5\% da superfície formada pela Formação Serra Geral, algo ao redor de $64.000 \mathrm{~km}^{2}$, e ocupam um volume de $15.300 \mathrm{~km}^{3}$, segundo dados de Nardy et. al. (2002), empregando as espessuras medidas no campo e cálculos em plataforma CAD. Os dados indicam também que o Membro Palmas é muito mais expressivo que o Chapecó, che- gando a representar $95 \%$ da área e $80 \%$ do volume total dessas unidades. Considerando o volume de lavas da Formação Serra Geral, 2,5\% desse total correspondem ao Membro Palmas e 0,5\% ao Membro Chapecó.

De maneira geral, as unidades ácidas encontram-se dispostas sobre os basaltos da Formação Serra Geral, exceção feita à região de Ourinhos, onde o Membro Chapecó assenta-se diretamente sobre os arenitos eólicos juro-cretáceos da Formação Botucatu. Os trabalhos de mapeamento geológico mostraram também que na região SW do Estado do Paraná, nos platôs de Generoso e Domingos Soares, na porção central da Bacia do Paraná, o Membro Chapecó encontra-se sobreposto diretamente ao Palmas, a indicar que nessa área as rochas do Membro Chapecó são mais jovens que as do tipo Palmas.

LITOGEOQUÍMICA Embora haja na literatura um grande acervo de dados geoquímicos de rochas vulcânicas ácidas, a sua utilização para estudos litogeoquímicos de maior detalhe encontra o inconveniente de as amostras não possuírem localizações geográficas confiáveis, ou então, provierem de autores distintos, sendo as informações disponíveis coligidas a partir de diferentes metologias e erros analíticos. Nesse contexto, um con-
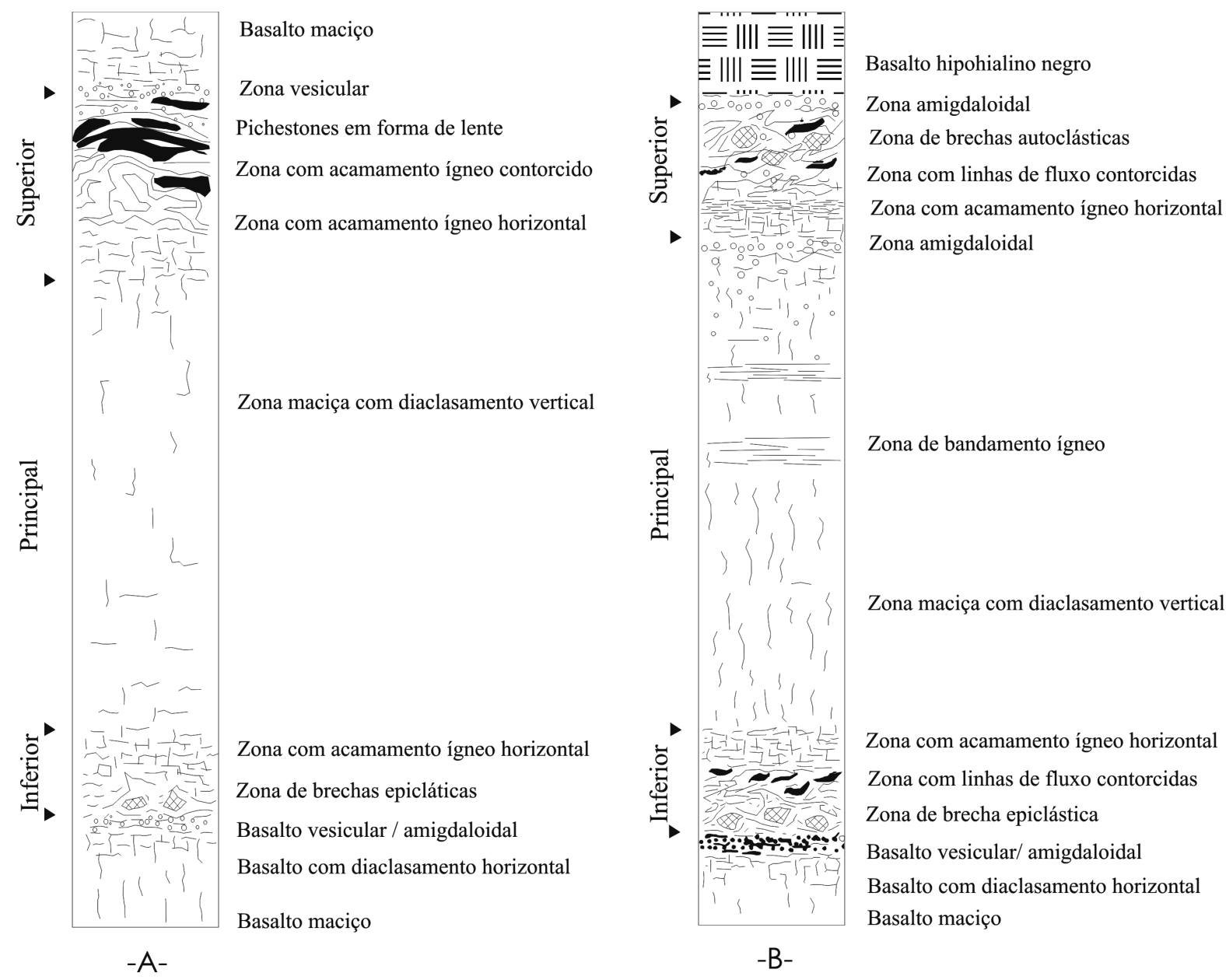

Figura 2 - Seções colunares características de seqüências de rochas vulcânicas ácidas dos tipos Palmas (A) e Chapecó (B). 
junto de 250 amostras de rochas ácidas, coletadas durante os trabalhos de campo realizados no programa de mapeamento geológico da Formação Serra Geral (Nar- dy el al., 2002), foi selecionado para o presente estudo. Essas amostras foram analisadas para elementos maiores, menores e traços por meio de fluorescência de raios

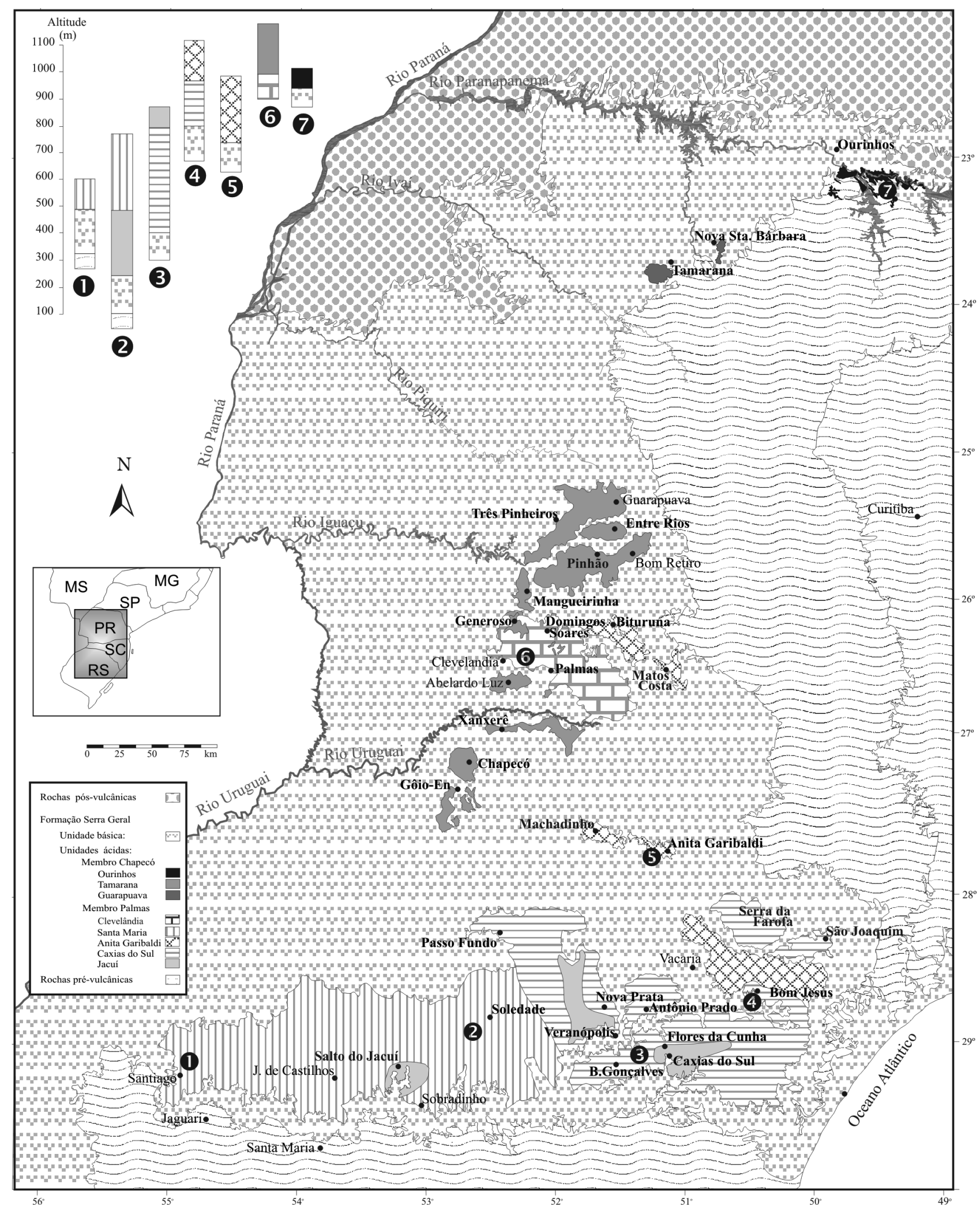

Figura 3 - Mapa litoestratigráfico dos Membros Palmas e Chapecó da Formação Serra Geral (modificado de Nardy et al., 2002). No detalhe, seções colunares representativas das associações litogeoquímicas observadas entre Jaguari-Santiago (1), Sobradinho-Soledade (2), Bento Gonçalves-Flores da Cunha (3), Bom Jesus-Vacaria (4), Machadinho-Anita Garibaldi (5), Clevelândia-Generoso (6), Rio Paranapanema-Ourinhos (7). 
X no Laboratório de Geoquímica do Departamento de Petrologia e Metalogenia do Instituto de Geociências e Ciências Exatas da Unesp. Para as determinações de elementos maiores e menores empregaram-se pastilhas fundidas em meio borato na proporção de 1:5 (cf. Nardy el al., 1997). Os elementos traços foram analisados a partir de pastilhas de pó, onde a amostra pulverizada a uma granulometria inferior a 200 mesh é misturada com cera micro pulverizada na proporção de 1:4, e prensada a $25 \mathrm{~T} / \mathrm{cm}^{2}$. Em algumas amostras, foram determinadas as concentrações de elementos terras raras por meio de ICP-OES, utilizando-se separação cromatográfica em resinas de troca iônica e nebulização ultrassônica, segundo metodologia descrita em Malagutti el al. (1998). Essas determinações foram também executadas no mesmo laboratório. A tabela 1 reúne os resultados obtidos em algumas amostras de rochas certificadas, onde é possível avaliar os erros analíticos envolvidos nas determinações. Por fim, foram também analisados os elementos $\mathrm{U}$ e Th de algumas amostras por meio de espectrometria gama no Departamento de Geofísica do IAG-USP, com os procedimentos analíticos empregados discutidos em Marques el al. (1993). Os resultados mais representativos das associações de rochas vulcânicas ácidas estão listados na tabela 2.

O caráter geral das rochas vulcânicas da Formação Serra Geral foi determinado por Piccirillo \& Melfi (1988) com o auxílio do diagrama R1R2 de De La Roche el al. (1980) (Fig. 4), onde se distingue a presença de dois grandes grupos de rochas, denominados de toleítico e tolético-transicional. O primeiro, disperso pelo campo toleítico, é constituído por basaltos com baixo teor em $\mathrm{Ti}\left(\mathrm{TiO}_{2}<2 \%\right)$ e por rochas ácidas do tipo Palmas; o segundo, também disposto no campo toleítico, porém, deslocado em direção ao transicional, é constituído por basaltos com alto teor em $\mathrm{Ti}\left(\mathrm{TiO}_{2} \geq 2 \%\right)$ e rochas ácidas do tipo Chapecó. É importante assinalar que as rochas da associação toleítica ocorrem preferencialmente na região sul da Bacia do Paraná, ou seja, aquela situada abaixo do Alinhamento do Rio Uruguai. Já as da associação toleítica-transicional estão presentes na região centro-norte da bacia, ou seja, acima daquele alinhamento, o que parece indicar a cogeneticidade entre as rochas de ambas associações.

Os dados geoquímicos ora obtidos demonstram que as rochas ácidas do tipo Palmas (ATP) não diferem daquelas do tipo Chapecó (ATC) apenas por seus aspectos petrográficos, mas apresentam também características geoquímicas bem distintas. De maneira geral, as do tipo Chapecó possuem intervalo de $\mathrm{SiO}_{2}$ entre $63,37 \%$ e $68,37 \%$, enquanto que nas do tipo Palmas ele é bem maior, indo de $63,00 \%$ a $72,07 \%$. Por outro lado, para um mesmo intervalo de $\mathrm{SiO}_{2}$, observa-se que as rochas do tipo Chapecó contêm maiores concentrações de álcalis (de 7,45\% a 8,34\%) em comparação com as do tipo Palmas (de 5,98\% a 8,64\%) (Fig. 5). Neste mesmo diagrama, é possível observar que as rochas do tipo Palmas estão dispostas no campo dos riodacitos e riolitos, enquanto que as do tipo Chapecó no campo dos traquitos (LeBas el al., 1986). Essas diferenças geoquímicas
Tabela 1 - Comparação entre os dados geoquímicos obtidos pelas técnicas analiticas empregadas neste trabalho com aqueles certificados para três materiais de referência internacional.

\begin{tabular}{|c|c|c|c|c|c|c|}
\hline & \multicolumn{2}{|c|}{ QLO-1 } & \multicolumn{2}{|c|}{ B-R } & \multicolumn{2}{|c|}{ RGM-1 } \\
\hline & obtido & certif. & obtido & certif. & obtido & certif. \\
\hline $\mathrm{SiO}_{2}$ & 66,36 & 66,20 & 39,56 & 39,52 & 73,74 & 74,03 \\
\hline $\mathrm{TiO}_{2}$ & 0,63 & 0,63 & 2,70 & 2,69 & 0,30 & 0,27 \\
\hline $\mathrm{Al}_{2} \mathrm{O}_{3}$ & 16,39 & 16,34 & 10,47 & 10,54 & 13,86 & 13,84 \\
\hline $\mathrm{Fe}_{2} \mathrm{O}_{3}$ & 4,46 & 4,39 & 13,39 & 13,33 & 1,90 & 1,88 \\
\hline $\mathrm{MnO}$ & 0,10 & 0,09 & 0,206 & 0,207 & 0,04 & 0,04 \\
\hline$M g O$ & 1,05 & 1,01 & 13,80 & 13,74 & 0,29 & 0,28 \\
\hline $\mathrm{CaO}$ & 3,23 & 3,20 & 14,25 & 14,28 & 1,23 & 1,16 \\
\hline $\mathrm{Na}_{2} \mathrm{O}$ & 4,29 & 4,24 & 3,18 & 3,17 & 4,12 & 4,11 \\
\hline $\mathrm{K}_{2} \mathrm{O}$ & 3,70 & 3,64 & 1,47 & 1,45 & 4,36 & 4,34 \\
\hline $\mathrm{P}_{2} \mathrm{O}_{5}$ & 0,26 & 0,26 & 1,09 & 1,08 & 0,05 & 0,05 \\
\hline Soma & 100,47 & 100,00 & 100,12 & 100,00 & 99,89 & 100,00 \\
\hline $\mathrm{Cu}$ & 30 & 29 & 72 & 72 & 11 & 12 \\
\hline $\mathrm{Ni}$ & 3 & 5 & 263 & 260 & 3 & 4 \\
\hline$B a$ & 1390 & 1370 & 1063 & 1050 & 796 & 807 \\
\hline$R b$ & 73 & 74 & 45 & 47 & 146 & 149 \\
\hline$S r$ & 332 & 336 & 1335 & 1320 & 104 & 108 \\
\hline$Z r$ & 192 & 185 & 256 & 260 & 230 & 219 \\
\hline$Y$ & 26 & 24 & 29 & 30 & 24 & 25 \\
\hline$N b$ & 11 & 10 & 98 & 98 & 10 & 9 \\
\hline$L a$ & 31 & 27 & & & 28 & 24 \\
\hline $\mathrm{Ce}$ & 50 & 54 & & & 44 & 47 \\
\hline$N d$ & 26 & 26 & & & 20 & 19 \\
\hline$S m$ & 5,3 & 4,9 & & & 4,5 & 4,3 \\
\hline$E u$ & 1,4 & 1,4 & & & 0,80 & 0,66 \\
\hline$G d$ & 4,6 & 4,7 & & & 3,5 & 3,7 \\
\hline$D y$ & 3,7 & 3,8 & & & 3,4 & 4,08 \\
\hline Ho & 0,83 & 0,86 & & & 0,77 & 0,95 \\
\hline$E r$ & 2,3 & 2,3 & & & 2,3 & 2,6 \\
\hline$Y b$ & 2,1 & 2,3 & & & 2,3 & 2,6 \\
\hline$L u$ & 0,30 & 0,37 & & & 0,35 & 0,41 \\
\hline
\end{tabular}

são também visíveis nos diagramas de Harker (Fig. 6), com as rochas do tipo ATC mostrando-se mais enriquecidas em $\mathrm{TiO}_{2}, \mathrm{P}_{2} \mathrm{O}_{5}, \mathrm{Al}_{2} \mathrm{O}_{3}$ e $\mathrm{Fe}_{2} \mathrm{O}_{3}$ e empobrecidas em $\mathrm{CaO}$ e $\mathrm{MgO}$ relativamente às do tipo ATP.

Quando se confrontam os padrões de distribuição dessas rochas em diagrama de concentrações re- 
Tabela 2 - Dados geoquímicos representativos das rochas ácidas estudadas.

\begin{tabular}{|c|c|c|c|c|c|c|c|c|c|c|c|c|c|c|c|c|}
\hline \multirow[b]{2}{*}{ Sigla } & \multicolumn{10}{|c|}{ Caxias do Sul } & \multicolumn{6}{|c|}{ Jacuí } \\
\hline & $\mathrm{KCF}$ & KSE & KPT & KSE & KSE & KLA & KS & $\mathrm{KS}$ & $\mathrm{KS}$ & KS & KSE & $\mathrm{KSC}$ & KSE & KSJ & KSJ & KSJ \\
\hline$n^{o}$ & 42 & 406 & 47 & 415 & 419 & 11 & 314 & 320 & 319 & 337 & 411 & 203 & 386 & 212 & 201 & 219 \\
\hline $\begin{array}{l}\text { Lat. } \\
(o)\end{array}$ & 29,455 & 29,202 & 29,188 & 29,232 & 28,670 & 28,192 & 28,282 & 28,373 & 28,360 & 28,915 & 29,091 & 29,394 & 29,367 & 29,405 & 29,217 & 28,408 \\
\hline $\begin{array}{l}\text { Long. } \\
\text { (o) }\end{array}$ & 50,582 & 51,271 & 50,223 & 50,374 & 50,304 & 50,716 & 49,961 & 49,986 & 49,971 & 50,459 & 50,825 & 53,038 & 52,990 & 53,250 & 53,095 & 53,901 \\
\hline $\begin{array}{l}\text { Cota } \\
\text { (m) } \\
\end{array}$ & 940 & 777 & 980 & 877 & 1041 & 925 & 1277 & 1237 & 1195 & 930 & 953 & 390 & 392 & 260 & 310 & 390 \\
\hline $\mathrm{SiO}_{2}$ & 66,25 & 66,44 & 66,78 & 67,04 & 67,58 & 67,63 & 67,99 & 68,06 & 68,70 & 69,08 & 64,84 & 65,22 & 65,70 & 66,33 & 66,88 & 68,12 \\
\hline $\mathrm{TiO}_{2}$ & 0,98 & 0,96 & 0,97 & 0,98 & 0,95 & 0,98 & 0,95 & 0,97 & 0,95 & 0,93 & 1,05 & 1,08 & 1,08 & 1,13 & 1,12 & 0,99 \\
\hline $\mathrm{Al}_{2} \mathrm{O}_{3}$ & 12,66 & 12,74 & 12,92 & 12,87 & 12,35 & 12,66 & 13,09 & 12,49 & 12,12 & 12,05 & 12,78 & 12,70 & 12,61 & 12,78 & 12,83 & 12,82 \\
\hline $\mathrm{Fe}_{2} \mathrm{O}_{3}$ & 6,19 & 6,15 & 6,05 & 6,18 & 6,15 & 6,23 & 5,98 & 6,46 & 5,69 & 6,08 & 6,90 & 7,10 & 6,86 & 6,93 & 7,07 & 6,16 \\
\hline $\mathrm{MnO}$ & 0,13 & 0,11 & 0,09 & 0,10 & 0,20 & 0,08 & 0,09 & 0,09 & 0,10 & 0,10 & 0,12 & 0,17 & 0,10 & 0,09 & 0,05 & 0,08 \\
\hline $\mathrm{MgO}$ & 1,32 & 1,70 & 1,36 & 1,51 & 1,22 & 1,55 & 1,29 & 1,08 & 1,28 & 1,27 & 1,40 & 1,41 & 1,27 & 1,29 & 0,99 & 0,83 \\
\hline $\mathrm{CaO}$ & 3,17 & 2,93 & 3,46 & 3,11 & 3,09 & 2,93 & 3,07 & 2,82 & 2,68 & 3,08 & 3,71 & 3,46 & 3,12 & 3,13 & 2,91 & 2,84 \\
\hline $\mathrm{Na}_{2} \mathrm{O}$ & 3,08 & 2,87 & 2,81 & 2,83 & 2,78 & 2,89 & 3,04 & 2,88 & 2,30 & 2,94 & 3,10 & 3,39 & 3,02 & 3,13 & 3,14 & 3,04 \\
\hline $\mathrm{K}_{2} \mathrm{O}$ & 3,82 & 3,89 & 4,01 & 4,06 & 4,17 & 3,90 & 4,29 & 3,95 & 4,69 & 3,75 & 3,64 & 3,66 & 3,86 & 3,97 & 3,76 & 4,09 \\
\hline $\mathrm{P}_{2} \mathrm{O}_{5}$ & 0,27 & 0,27 & 0,26 & 0,27 & 0,26 & 0,26 & 0,27 & 0,27 & 0,26 & 0,26 & 0,28 & 0,30 & 0,29 & 0,29 & 0,30 & 0,27 \\
\hline LOI & 1,19 & 1,91 & 1,92 & 0,98 & 1,01 & 0,89 & 0,56 & 1,14 & 0,99 & 0,70 & 1,97 & 0,96 & 1,23 & 1,03 & 1,57 & 0,75 \\
\hline Soma & 99,06 & 99,98 & 100,63 & 99,92 & 99,75 & 100,02 & 100,62 & 100,19 & 99,76 & 100,25 & 99,79 & 99,44 & 99,14 & 100,09 & 100,62 & 99,99 \\
\hline $\mathrm{Cu}$ & 68 & 75 & 76 & 73 & 78 & 69 & 57 & 68 & 63 & 79 & 57 & 67 & 77 & 61 & 76 & 82 \\
\hline $\mathrm{Ni}$ & 7 & 8 & 7 & 8 & 7 & 7 & 8 & 8 & 8 & 8 & 5 & 9 & 8 & 7 & 9 & 6 \\
\hline $\mathrm{Ba}$ & 569 & 706 & 535 & 637 & 694 & 558 & 603 & 617 & 588 & 517 & 572 & 553 & 569 & 538 & 538 & 576 \\
\hline $\mathrm{Rb}$ & 157 & 160 & 159 & 167 & 165 & 152 & 177 & 160 & 175 & 158 & 170 & 155 & 182 & 174 & 166 & 173 \\
\hline $\mathrm{Sr}$ & 132 & 143 & 148 & 138 & 127 & 120 & 145 & 126 & 137 & 134 & 152 & 155 & 152 & 146 & 152 & 152 \\
\hline $\mathrm{Zr}$ & 247 & 258 & 248 & 263 & 252 & 231 & 270 & 252 & 266 & 245 & 272 & 270 & 257 & 257 & 264 & 258 \\
\hline Y & 39 & 41 & 40 & 40 & 57 & 32 & 44 & 40 & 42 & 38 & 43 & 44 & 53 & 41 & 39 & 46 \\
\hline $\mathrm{Nb}$ & 20 & 20 & 20 & 20 & 20 & 18 & 23 & 20 & 21 & 19 & 20 & 22 & 19 & 20 & 19 & 20 \\
\hline U & & 4,07 & 5,19 & & 4,04 & 4,54 & 4,16 & 4,34 & 4,17 & & & 4,04 & & 4,74 & & \\
\hline Th & & 11,30 & 14,90 & & 11,64 & 13,35 & 11,22 & 11,79 & 12,09 & & & 11,64 & & 12,23 & & \\
\hline $\mathrm{La}$ & & 35,0 & 40,0 & & 36,1 & 32,8 & 37,0 & 37,0 & 36,0 & & & 35,0 & & 38,0 & & \\
\hline $\mathrm{Ce}$ & & 76,0 & 92,0 & & 78,0 & 71,1 & 75,0 & 79,0 & 73,0 & & & 78,0 & & 79,0 & & \\
\hline $\mathrm{Nd}$ & & 36,0 & 44,0 & & 34,8 & 31,1 & 35,0 & 37,0 & 34,0 & & & 34,0 & & 37,0 & & \\
\hline $\mathrm{Sm}$ & & 7,00 & 9,30 & & 7,47 & 6,81 & 7,00 & 7,30 & 7,10 & & & 6,70 & & 7,30 & & \\
\hline $\mathrm{Eu}$ & & 1,66 & 1,84 & & 1,53 & 1,39 & 1,70 & 1,70 & 1,53 & & & 1,53 & & 1,59 & & \\
\hline Gd & & 7,30 & 9,20 & & 7,28 & 6,13 & 6,50 & 7,00 & 8,10 & & & 6,60 & & 7,10 & & \\
\hline Dy & & 6,90 & 8,80 & & 7,43 & 6,12 & 6,00 & 6,50 & 7,40 & & & 6,30 & & 6,80 & & \\
\hline Ho & & 1,40 & 1,80 & & & & 1,20 & 1,30 & 1,60 & & & 1,40 & & 1,50 & & \\
\hline Er & & 4,00 & 5,10 & & 4,54 & 3,40 & 3,40 & 3,70 & 4,60 & & & 3,80 & & 4,30 & & \\
\hline $\mathrm{Yb}$ & & 3,40 & 4,80 & & 3,92 & 3,01 & 3,20 & 3,10 & 3,70 & & & 3,30 & & 3,50 & & \\
\hline $\mathrm{Lu}$ & & 0,50 & 0,70 & & 0,61 & 0,45 & 0,40 & 0,50 & 0,60 & & & 0,50 & & 0,50 & & \\
\hline
\end{tabular}


Tabela 2 - Continuação.

\begin{tabular}{|c|c|c|c|c|c|c|c|c|c|c|c|c|c|c|c|c|}
\hline & \multicolumn{5}{|c|}{ Anita Garibaldi } & \multicolumn{5}{|c|}{ Santa Maria } & \multicolumn{6}{|c|}{ Clevelândia } \\
\hline Sigla & $\mathrm{KC}$ & KSE & KSE & $\mathrm{KC}$ & KS & $\mathrm{KSU}$ & $\mathrm{KSU}$ & $\mathrm{KSU}$ & KSS & $\mathrm{KSC}$ & $\mathrm{HI}$ & $\mathrm{KCP}$ & $\mathrm{HI}$ & $\mathrm{KC}$ & $\mathrm{K}$ & $\mathrm{HI}$ \\
\hline$n^{o}$ & 505 & 361 & 363 & 502 & 313 & 235 & 239 & 237 & 195 & 204 & 83 & 266 & 54 & 478 & 2065 & 64 \\
\hline $\begin{array}{l}\text { Lat. } \\
\text { (o) }\end{array}$ & 27,537 & 27,664 & 27,633 & 27,429 & 28,246 & 29,250 & 29,365 & 29,018 & 28,824 & 29,418 & 26,800 & 26,568 & 26,593 & 26,157 & 26,635 & 26,648 \\
\hline $\begin{array}{l}\text { Long. } \\
\text { (o) }\end{array}$ & 51,089 & 51,457 & 51,610 & 51,131 & 50,776 & 54,824 & 54,686 & 54,759 & 52,676 & 53,009 & 51,682 & 51,918 & 51,453 & 52,192 & 51,688 & 51,513 \\
\hline $\begin{array}{l}\text { Cota } \\
\text { (m) }\end{array}$ & 943 & 716 & 740 & 806 & 896 & 500 & 335 & 415 & 650 & 455 & 1265 & 1176 & 1320 & 929 & 1230 & 1280 \\
\hline $\mathrm{SiO}_{2}$ & 65,48 & 66,00 & 66,45 & 67,10 & 67,70 & 69,60 & 70,26 & 70,46 & 70,53 & 71,04 & 68,83 & 69,51 & 69,78 & 70,21 & 71,37 & 72,07 \\
\hline $\mathrm{TiO}_{2}$ & 1,11 & 1,10 & 1,09 & 1,08 & 1,06 & 0,74 & 0,74 & 0,71 & 0,70 & 0,71 & 0,87 & 0,77 & 0,77 & 0,79 & 0,74 & 0,72 \\
\hline $\mathrm{Al}_{2} \mathrm{O}_{3}$ & 12,96 & 12,56 & 12,54 & 12,68 & 12,56 & 12,56 & 12,23 & 12,38 & 12,24 & 12,49 & 12,16 & 12,26 & 12,34 & 12,29 & 12,01 & $11 . .65$ \\
\hline $\mathrm{Fe}_{2} \mathrm{O}_{3}$ & 6,78 & 6,63 & 6,41 & 6,62 & 6,41 & 5,42 & 5,15 & 5,22 & 5,41 & 5,12 & 5,54 & 5,58 & 5,49 & 5,67 & 5,15 & 5,14 \\
\hline $\mathrm{MnO}$ & 0,08 & 0,12 & 0,11 & 0,09 & 0,08 & 0,09 & 0,07 & 0,09 & 0,08 & 0,04 & 0,12 & 0,09 & 0,10 & 0,09 & 0,08 & 0,05 \\
\hline $\mathrm{MgO}$ & 1,08 & 1,32 & 1,22 & 1,19 & 1,45 & 0,92 & 0,55 & 0,61 & 0,66 & 0,59 & 1,11 & 0,88 & 0,73 & 0,68 & 0,69 & 0,32 \\
\hline $\mathrm{CaO}$ & 2,78 & 3,34 & 3,11 & 3,11 & 2,86 & 1,69 & 1,76 & 2,20 & 1,84 & 1,77 & 1,87 & 2,08 & 2,15 & 2,07 & 1,99 & 1,29 \\
\hline $\mathrm{Na}_{2} \mathrm{O}$ & 3,64 & 3,19 & 3,32 & 3,16 & 3,21 & 2,50 & 2,59 & 2,92 & 2,83 & 2,75 & 2,62 & 2,64 & 2,84 & 2,77 & 2,69 & 2,45 \\
\hline $\mathrm{K}_{2} \mathrm{O}$ & 4,01 & 4,06 & 4,10 & 3,87 & 3,96 & 4,83 & 5,03 & 4,74 & 4,85 & 4,56 & 4,59 & 4,87 & 4,88 & 4,80 & 4,85 & 4,78 \\
\hline $\mathrm{P}_{2} \mathrm{O}_{5}$ & 0,33 & 0,32 & 0,32 & 0,33 & 0,32 & 0,21 & 0,21 & 0,20 & 0,20 & 0,20 & 0,22 & 0,21 & 0,21 & 0,22 & 0,20 & 0,20 \\
\hline LOI & 1,93 & 0,83 & 0,98 & 1,58 & 0,82 & 1,68 & 1,23 & 0,57 & 1,27 & 1,21 & 1,52 & 1,06 & 1,00 & 0,79 & 0,63 & 1,22 \\
\hline Soma & 100,17 & 99,47 & 99,64 & 100,80 & 100,42 & 100,24 & 99,81 & 100,09 & 100,61 & 100,48 & 99,46 & 99,95 & 100,29 & 100,40 & 100,40 & 99,57 \\
\hline $\mathrm{Cu}$ & 128 & 228 & 117 & 130 & 140 & 26 & 23 & 18 & 22 & 30 & 24 & 26 & 22 & 27 & 31 & 27 \\
\hline $\mathrm{Ni}$ & 7 & 6 & 7 & 8 & 9 & 6 & 5 & 3 & 7 & 5 & 4 & 5 & 4 & 6 & 3 & 2 \\
\hline $\mathrm{Ba}$ & 610 & 552 & 602 & 571 & 531 & 619 & 679 & 613 & 638 & 646 & 680 & 633 & 652 & 642 & 629 & 625 \\
\hline $\mathrm{Rb}$ & 169 & 154 & 170 & 158 & 158 & 200 & 213 & 206 & 208 & 209 & 197 & 213 & 207 & 207 & 197 & 206 \\
\hline $\mathrm{Sr}$ & 135 & 142 & 137 & 143 & 130 & 95 & 96 & 102 & 94 & 96 & 92 & 102 & 99 & 103 & 95 & 77 \\
\hline $\mathrm{Zr}$ & 279 & 280 & 274 & 277 & 272 & 314 & 326 & 319 & 336 & 327 & 331 & 323 & 320 & 334 & 312 & 308 \\
\hline Y & 63 & 47 & 67 & 63 & 54 & 51 & 61 & 55 & 58 & 54 & 61 & 65 & 72 & 57 & 56 & 56 \\
\hline $\mathrm{Nb}$ & 22 & 23 & 21 & 22 & 20 & 23 & 24 & 23 & 25 & 23 & 24 & 23 & 24 & 26 & 25 & 22 \\
\hline $\mathrm{U}$ & 3,51 & 3,91 & 3,74 & & & & & 3,25 & 4,10 & & 5,40 & & 4,10 & & & \\
\hline Th & 11,53 & 11,40 & 11,39 & & & & & 12,25 & 16,77 & & 17,63 & & 17,33 & & & \\
\hline $\mathrm{La}$ & 42,0 & 37,0 & 39,0 & & & & & 43,2 & 45,4 & & 44,6 & & 45,2 & & & \\
\hline $\mathrm{Ce}$ & 88,0 & 77,0 & 82,0 & & & & & 95,5 & 97,8 & & 95,8 & & 93,4 & & & \\
\hline $\mathrm{Nd}$ & 46,0 & 38,0 & 41,0 & & & & & 42,7 & 42,8 & & 42,6 & & 43,8 & & & \\
\hline $\mathrm{Sm}$ & 9,40 & 7,70 & 8,10 & & & & & 8,78 & 9,61 & & 9,46 & & 9,86 & & & \\
\hline $\mathrm{Eu}$ & 2,02 & 1,72 & 1,78 & & & & & 1,60 & 1,70 & & 1,72 & & 1,79 & & & \\
\hline Gd & 9,80 & 7,50 & 8,00 & & & & & 8,78 & 9,07 & & 9,08 & & 9,94 & & & \\
\hline Dy & 8,30 & 7,50 & 7,60 & & & & & 8,32 & 9,09 & & 9,26 & & 10,50 & & & \\
\hline Ho & 1,70 & 1,50 & 1,60 & & & & & & & & & & & & & \\
\hline Er & 4,70 & 4,50 & 4,50 & & & & & 5,25 & 5,48 & & 5,55 & & 6,38 & & & \\
\hline $\mathrm{Yb}$ & 4,50 & 4,10 & 4,00 & & & & & 4,61 & 4,98 & & 4,84 & & 5,36 & & & \\
\hline $\mathrm{Lu}$ & 0,60 & 0,60 & 0,50 & & & & & 0,71 & 0,79 & & 0,75 & & 0,83 & & & \\
\hline
\end{tabular}


Tabela 2 - Continuação.

\begin{tabular}{|c|c|c|c|c|c|c|c|c|c|c|c|c|c|c|}
\hline & \multicolumn{8}{|c|}{ Guarapuava } & \multicolumn{2}{|c|}{ Tamarana } & \multicolumn{4}{|c|}{ Ourinhos } \\
\hline Sigla & PU & $\mathrm{KC}$ & $\mathrm{KC}$ & $\mathrm{K}$ & $\mathrm{HI}$ & $\mathrm{K}$ & $\mathrm{KC}$ & PU & KNT & KNA & KNO & $\mathrm{KNO}$ & $\mathrm{KNO}$ & $\mathrm{KNO}$ \\
\hline$n^{o}$ & 1005 & 481 & 482 & 2031 & 98 & 2007 & 486 & 1069 & 453 & 128 & 438 & 448 & 450 & 436 \\
\hline Lat.(o) & 25,427 & 27,247 & 27,303 & 26,045 & 26,914 & 27,149 & 23,394 & 25,925 & 23,786 & 23,725 & 23,112 & 23,176 & 23,099 & 23,099 \\
\hline Long.(o) & 51,487 & 52,684 & 52,660 & 52,208 & 51,768 & 52,649 & 52,690 & 51,591 & 51,156 & 50,738 & 49,751 & 49,630 & 49,493 & 49,747 \\
\hline $\operatorname{Cota}(m)$ & 1083 & 518 & 589 & 940 & 1135 & 607 & 646 & 1202 & 710 & 880 & 497 & 748 & 641 & 431 \\
\hline $\mathrm{SiO}_{2}$ & 63,63 & 64,00 & 64,38 & 64,66 & 65,02 & 65,40 & 65,48 & 65,87 & 63,60 & 64,29 & 65,64 & 65,00 & 66,05 & 68,37 \\
\hline $\mathrm{TiO}_{2}$ & 1,47 & 1,53 & 1,46 & 1,53 & 1,54 & 1,48 & 1,46 & 1,48 & 1,47 & 1,38 & 1,25 & 1,16 & 1,21 & 1,18 \\
\hline $\mathrm{Al}_{2} \mathrm{O}_{3}$ & 13,20 & 13,10 & 12,83 & 13,51 & 13,14 & 12,89 & 12,57 & 12,54 & 13,51 & 13,50 & 13,25 & 12,92 & 13,06 & 12,64 \\
\hline $\mathrm{Fe}_{2} \mathrm{O}_{3}$ & 7,74 & 7,36 & 7,01 & 7,34 & 7,37 & 7,19 & 7,17 & 7,24 & 6,91 & 7,65 & 6,92 & 6,51 & 6,86 & 5,98 \\
\hline $\mathrm{MnO}$ & 0,16 & 0,14 & 0,16 & 0,12 & 0,10 & 0,13 & 0,14 & 0,12 & 0,15 & 0,11 & 0,12 & 0,47 & 0,11 & 0,05 \\
\hline $\mathrm{MgO}$ & 1,28 & 1,25 & 1,36 & 1,42 & 1,58 & 1,31 & 1,30 & 1,27 & 1,26 & 1,26 & 1,12 & 0,72 & 1,16 & 0,41 \\
\hline $\mathrm{CaO}$ & 2,98 & 3,21 & 2,91 & 3,11 & 2,96 & 3,04 & 2,81 & 2,55 & 2,85 & 3,05 & 2,61 & 3,92 & 2,59 & 1,69 \\
\hline $\mathrm{Na}_{2} \mathrm{O}$ & 3,65 & 3,43 & 3,32 & 3,59 & 3,43 & 3,47 & 3,37 & 3,60 & 3,58 & 3,79 & 3,56 & 3,39 & 3,32 & 3,22 \\
\hline $\mathrm{K}_{2} \mathrm{O}$ & 4,24 & 4,78 & 4,45 & 4,08 & 4,40 & 4,09 & 4,08 & 4,29 & 4,46 & 4,16 & 4,53 & 4,36 & 4,40 & 5,03 \\
\hline $\mathrm{P}_{2} \mathrm{O}_{5}$ & 0,45 & 0,47 & 0,48 & 0,47 & 0,47 & 0,47 & 0,47 & 0,44 & 0,47 & 0,41 & 0,34 & 0,33 & 0,33 & 0,34 \\
\hline LOI & 0,83 & 1,04 & 1,05 & 0,80 & 0,98 & 1,13 & 0,91 & 0,78 & 1,12 & 0,83 & 0,86 & 1,38 & 1,24 & 1,28 \\
\hline Soma & 99,64 & 100,31 & 99,41 & 100,62 & 100,98 & 100,60 & 99,77 & 100,19 & 99,37 & 100,40 & 100,19 & 100,16 & 100,32 & 100,20 \\
\hline $\mathrm{Cu}$ & 7 & 9 & 7 & 7 & 7 & 6 & 7 & 9 & 7 & 7 & 16 & 16 & 13 & 14 \\
\hline $\mathrm{Ni}$ & 3 & 8 & 4 & 4 & 4 & 2 & 6 & 2 & 6 & 5 & 6 & 7 & 6 & 6 \\
\hline $\mathrm{Ba}$ & 1071 & 1052 & 1076 & 990 & 960 & 1003 & 1038 & 968 & 1037 & 1106 & 1063 & 1264 & 1236 & 1034 \\
\hline $\mathrm{Rb}$ & 100 & 109 & 100 & 93 & 102 & 93 & 97 & 100 & 100 & 110 & 134 & 128 & 118 & 140 \\
\hline $\mathrm{Sr}$ & 383 & 373 & 360 & 378 & 382 & 364 & 383 & 335 & 355 & 391 & 328 & 355 & 319 & 305 \\
\hline $\mathrm{Zr}$ & 660 & 658 & 633 & 658 & 648 & 624 & 644 & 648 & 670 & 595 & 595 & 592 & 544 & 582 \\
\hline $\mathrm{Y}$ & 68 & 69 & 65 & 66 & 66 & 60 & 62 & 62 & 96 & 64 & 64 & 94 & 51 & 50 \\
\hline $\mathrm{Nb}$ & 50 & 51 & 48 & 51 & 50 & 50 & 49 & 50 & 52 & 45 & 46 & 45 & 41 & 45 \\
\hline U & & & 1,74 & & 1,97 & 1,75 & & 2,02 & 2,04 & 2,32 & 3,08 & 2,69 & 2,91 & \\
\hline Th & & & 8,76 & & 8,79 & 8,72 & & 8,90 & 9,14 & 10,29 & 13,04 & 12,02 & 12,81 & \\
\hline $\mathrm{La}$ & & & 60,4 & & 62,0 & 64,2 & & 64,0 & & 62,0 & 67,4 & 64,81 & 64,36 & \\
\hline $\mathrm{Ce}$ & & & 144,6 & & 140,0 & 147,5 & & 133,0 & & 140,3 & 149,1 & 143,14 & 148,65 & \\
\hline $\mathrm{Nd}$ & & & 68,4 & & 68,4 & 71,8 & & 72,0 & & 68,3 & 68,3 & 69,68 & 66,36 & \\
\hline $\mathrm{Sm}$ & & & 15,78 & & 15,30 & 15,53 & & 14,30 & & 15,07 & 14,08 & 14,12 & 14,19 & \\
\hline $\mathrm{Eu}$ & & & 3,60 & & 3,55 & 3,50 & & 4,40 & & 3,35 & 3,17 & 2,99 & 3,02 & \\
\hline Gd & & & 14,04 & & 13,20 & 13,23 & & & & 13,26 & 12,34 & 13,29 & 11,98 & \\
\hline Dy & & & 10,83 & & 11,50 & 11,21 & & & & 11,05 & 10,47 & 11,55 & 10,16 & \\
\hline \multicolumn{15}{|l|}{ Ho } \\
\hline Er & & & 5,97 & & 5,94 & 5,72 & & & & 5,99 & 5,65 & 6,82 & 5,54 & \\
\hline $\mathrm{Yb}$ & & & 4,79 & & 4,83 & 4,53 & & 5,60 & & 4,76 & 4,47 & 4,83 & 4,60 & \\
\hline $\mathrm{Lu}$ & & & 0,65 & & 0,72 & 0,63 & & 0,79 & & 0,66 & 0,63 & 0,70 & 0,62 & \\
\hline
\end{tabular}



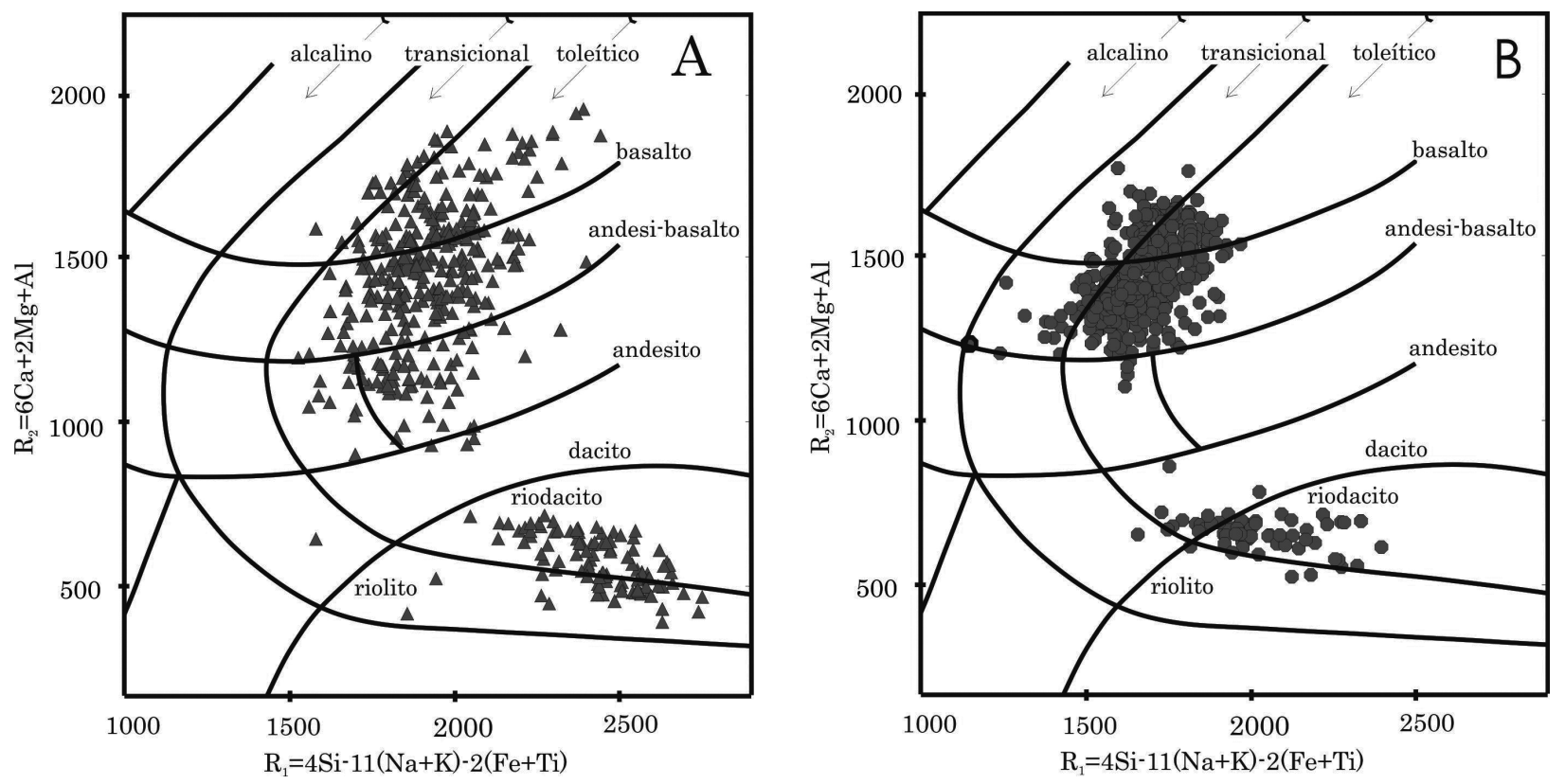

Figura 4 - Diagrama R1R2 (cf. De La Roche el al.,1980) para as rochas vulcânicas da Bacia do Paraná: A. Associação toleítica (basaltos, andesi-basaltos e andesito toleíticos com $\mathrm{TiO}_{2}<2 \%$; riodacitos e riolitos do tipo Palmas) e B. Associação toleitica-transicional (basaltos toleíticos e transicionais, andesi-basaltos toleiticos, lati-basaltos; dacitos e riodacitos do tipo Chapecó). Dados de Piccirillo \& Melfi (1988).

lativas ao manto primordial (cf. Sun \& McDonough, 1989; Fig. 7), nota-se que as do tipo ATC são mais ricas em $\mathrm{Ba}, \mathrm{Nb}, \mathrm{La}, \mathrm{Ce}, \mathrm{Zr}, \mathrm{P} . \mathrm{Nd}, \mathrm{Y}, \mathrm{Yb}, \mathrm{Lu}$ e $\mathrm{K}$ e mais pobres em $\mathrm{Rb}$, Th e U quando comparadas às do tipo ATP. Apesar dos padrões serem bastante parecidos para ambas as associações, as últimas apresentam maiores relações $\mathrm{Rb} / \mathrm{Ba}, \mathrm{U} / \mathrm{Nb}$ e $\mathrm{Ce} / \mathrm{Sr}$ relativamente do tipo ATC. No mesmo diagrama, verifica-se que as do tipo ATC tem maior relação $\mathrm{La} / \mathrm{Lu}(10,37)$ em comparação com aquelas do tipo ATP $(7,04)$.

Segundo Garland el al. (1995), as rochas do tipo ATP são derivadas da fusão parcial de basaltos do tipo Gramado, enquanto as do tipo ATC da fusão parcial de basaltos do tipo Pitanga, cujas composições em termos de elementos traços foram igualmente projetadas no gráfico da figura 7, juntamente com a média da composição da crosta continental superior (Taylor \& McLennan, 1981), que parece ter também exercido uma forte influência na evolução das rochas vulcânicas.

As Rochas Ácidas do Tipo Palmas Estudos prévios de Bellieni el al. (1986), Peate el al. (1992) e Garland el al. (1995) sobre a geoquímica das rochas ácidas do tipo Palmas revelaram que elas não são homogêneas. De fato, são reconhecidos dois grandes grupos, conforme indica o diagrama da figura 8 . Um deles, baixo em Ti $\left(\mathrm{TiO}_{2} \leq 0,87 \%\right)$, é formado por dois subgrupos, ou subtipos, distintos, denominados Santa Maria $\left(\mathrm{P}_{2} \mathrm{O}_{5} \leq 0,21 \%\right)$ e Clevelândia $\left(0,21 \%<\mathrm{P}_{2} \mathrm{O}_{5} \leq 0,23 \%\right)$. O subgrupo Santa Maria, definido por Peate el al. (1992), cobre área aproximada de $12.300 \mathrm{~km}^{2}$ distribuída de forma praticamente contínua na porção centro-oeste do Estado do

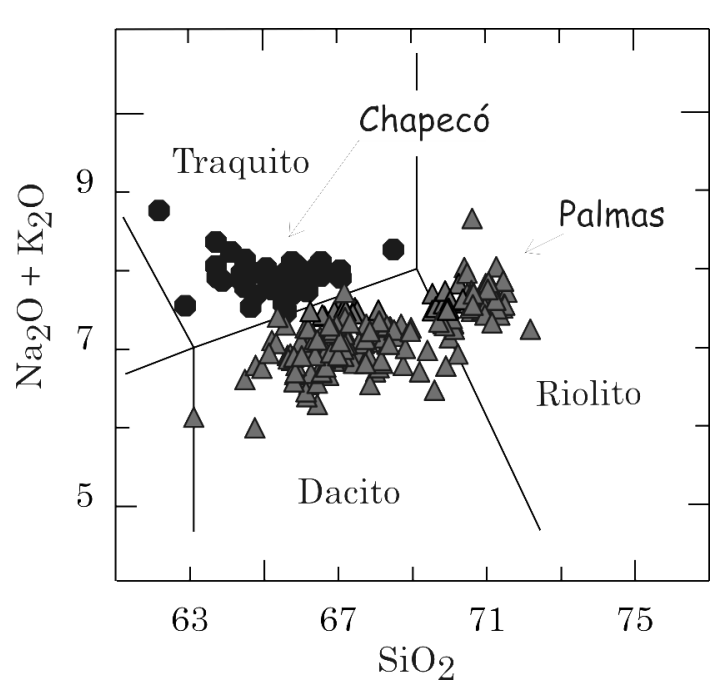

Figura 5 - Classificação e nomenclatura das rochas vulcânicas ácidas dos tipos Palmas (triângulos) e Chapecó (círculos) segundo o diagrama TAS (Le Bas el al., 1986).

Rio Grande do Sul, entre as cidades de Santiago e Soledade, com espessuras variando, respectivamente, entre $150 \mathrm{~m}$ e $450 \mathrm{~m}$, resultando $4.500 \mathrm{~km}^{3}$ de lavas.

O outro subgrupo, Clevelândia, ocorre em um platô de $4.087 \mathrm{~km}^{2}$, que se estende das proximidades de de General Carneiro até Clevelândia, ao sul do Estado do Paraná. Apresenta espessura média de $150 \mathrm{~m}$ e volume da ordem de $613 \mathrm{~km}^{3}$ (Fig. 3). 

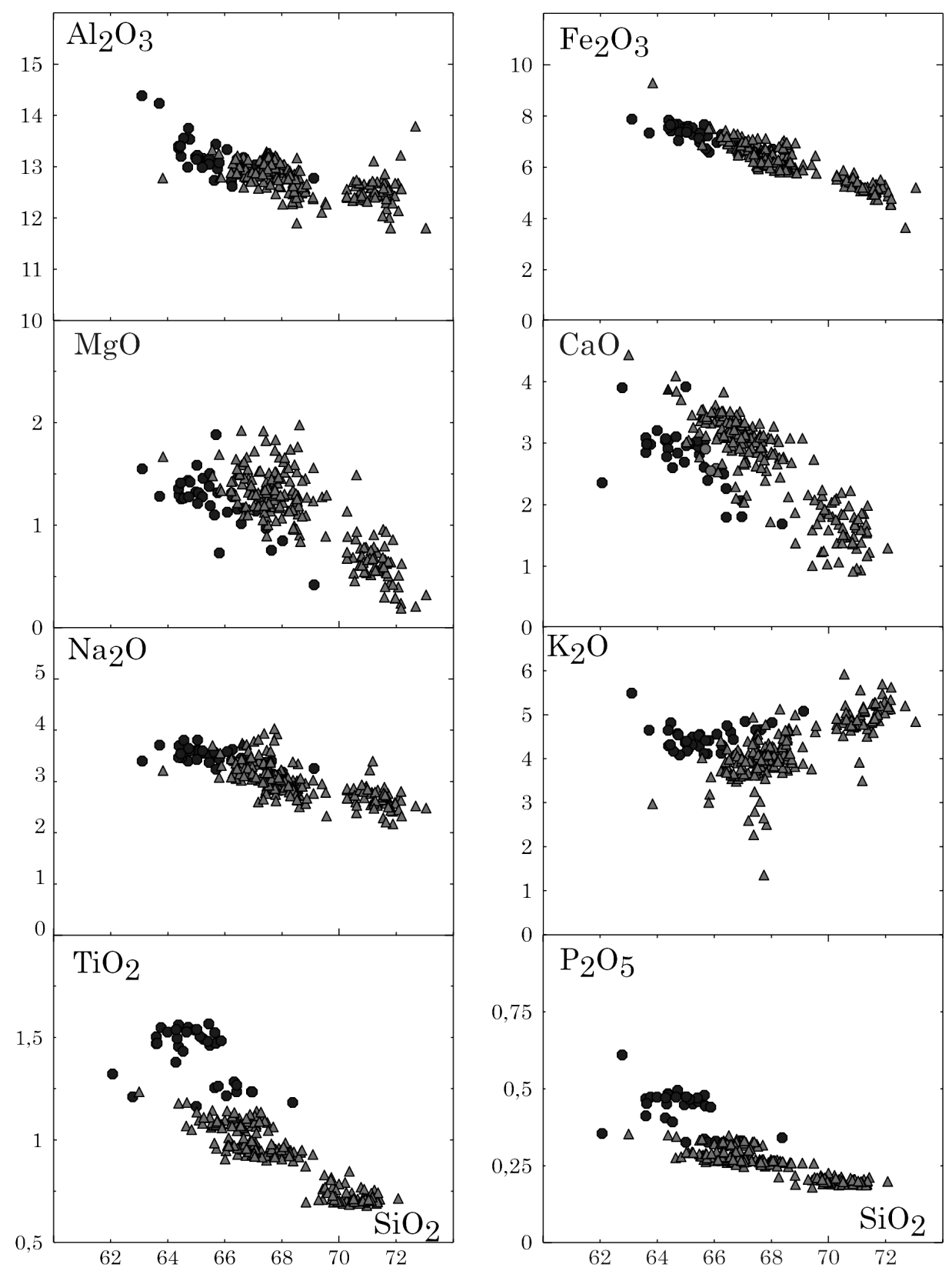

Figura 6 - Diagramas de Harker para elementos maiores e menores das rochas ácidas dos tipos Palmas e Chapecó. Símbolos como na figura 5.

O grupo alto em $\mathrm{Ti}_{(}\left(\mathrm{TiO}_{2} \geq 0,90 \%\right)$ é representado por três subgrupos, ou subtipos, denominados Caxias do Sul $\left(0,91 \%<\mathrm{TiO}_{1}<1,03 \%\right.$ e $\left.0,25 \%<\mathrm{P}_{2} \mathrm{O}_{5}<0,28 \%\right)$, Anita Garibaldi $\left(1,06 \%<\mathrm{TiO}<1,25 \%\right.$ e $\left.0,32 \%<\mathrm{P}_{2} \mathrm{O}_{5}<0,36 \%\right)$ e Jacuí $\left(1,05 \%<\mathrm{TiO}_{2}<1,16 \%\right.$ e $\left.0,28 \%<\mathrm{P}_{2} \mathrm{O}_{5}<0,31 \%\right)$. O subtipo Caxias do Sul foi inicialmente reconhecido por Peate el al. (1992) e recobre área total de $16.000 \mathrm{~km}^{2} \mathrm{e}$ ocupa volume de $4.832 \mathrm{~km}^{3}$, sendo observado em cinco platôs distintos denominados de Serra da Farofa (1.384 $\mathrm{km}^{2}$ e $\left.304 \mathrm{~km}^{3}\right)$, São Joaquim $\left(580 \mathrm{~km}^{2}\right.$ e $\left.230 \mathrm{~km}^{3}\right)$, Bento Gonçalves, $\left(8.929 \mathrm{~km}^{2}\right.$ e $\left.2.257 \mathrm{~km}^{3}\right)$, Antonio Prado $\left(1.133 \mathrm{~km}^{2}\right.$ e $\left.453 \mathrm{~km}^{3}\right)$ e Nova Prata $\left(3.974 \mathrm{~km}^{2}\right.$ e $1.588 \mathrm{~km}^{3}$ ). O subtipo Anita Garibaldi, individualizado por Garland el al. (1995), cobre área de $4.486 \mathrm{~km}^{2}$ e ocupa volume de $1.008 \mathrm{~km}^{3}$. Ele está representado por cinco platôs distintos, distribuídos pelos estados do
Paraná (Bituruna, $716 \mathrm{~km}^{2}$ e $84 \mathrm{~km}^{3}$ ), Santa Catarina (Matos Costa, $241 \mathrm{~km}^{2}$ e $42 \mathrm{~km}^{3}$; Machadinho, $366 \mathrm{~km}^{2}$ e $99 \mathrm{~km}^{3}$; Anita Garibaldi, $246 \mathrm{~km}^{2}$ e $54 \mathrm{~km}^{3}$ ) e Rio Grande do Sul (o maior de todos, Bom Jesus, $2.917 \mathrm{~km}^{2}$ e $729 \mathrm{~km}^{3}$ ). Por fim, o subtipo Jacuí, que recobre área aproximada de $3.451 \mathrm{~km}^{2}$, com um volume de 1.058 $\mathrm{km}^{3}$, que se estende por três regiões distintas no estado do Rio Grande do Sul (Flores da Cunha, $961 \mathrm{~km}^{2}$ e 398 $\mathrm{km}^{3}$; Veranópolis, $1.326 \mathrm{~km}^{2}$ e $544 \mathrm{~km}^{3}$; Salto do Jacuí, $\left.1.164 \mathrm{~km}^{2} \mathrm{e} 116 \mathrm{~km}^{3}\right)$.

Além de ocorrerem em diversas regiões na $\mathrm{Ba}-$ cia do Paraná, essas rochas apresentam pequenas diferenças em suas composições geoquímicas, ao lado daquelas assinaladas na figura 8. Os diagramas de Harker (Fig. 9) indicam que cada um dos subtipos definem trends distintos entre si, mostrando, inclusive, que para 


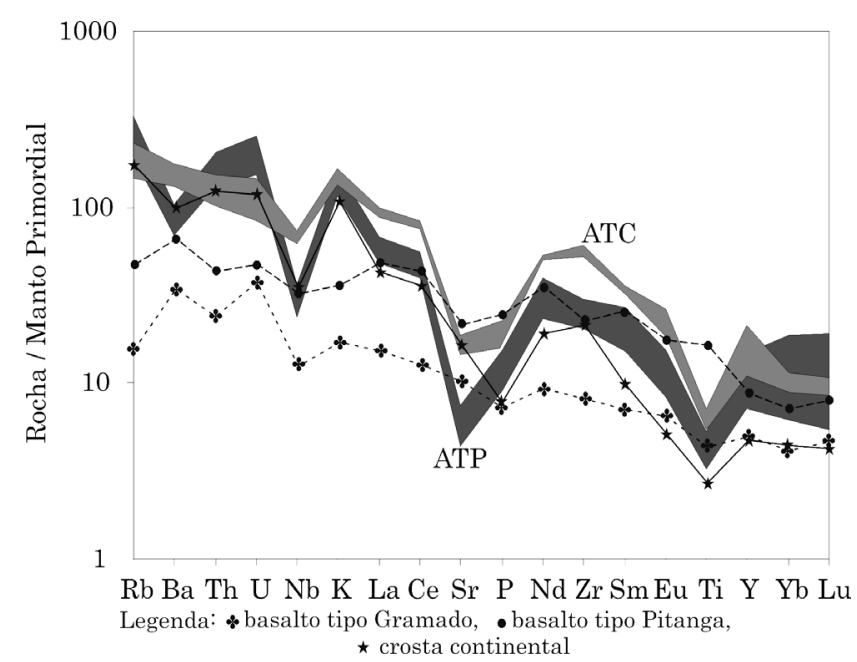

Figura 7 - Diagrama de elementos incompativeis normalizados em relação ao manto primordial (Sun \& McDonough, 1989) das rochas ácidas dos tipos Palmas e Chapecó, composição média da crosta continental (Taylor \& McLennan, 1981) e basaltos dos tipos Gramado e Pitanga (Garland el al. 1995).
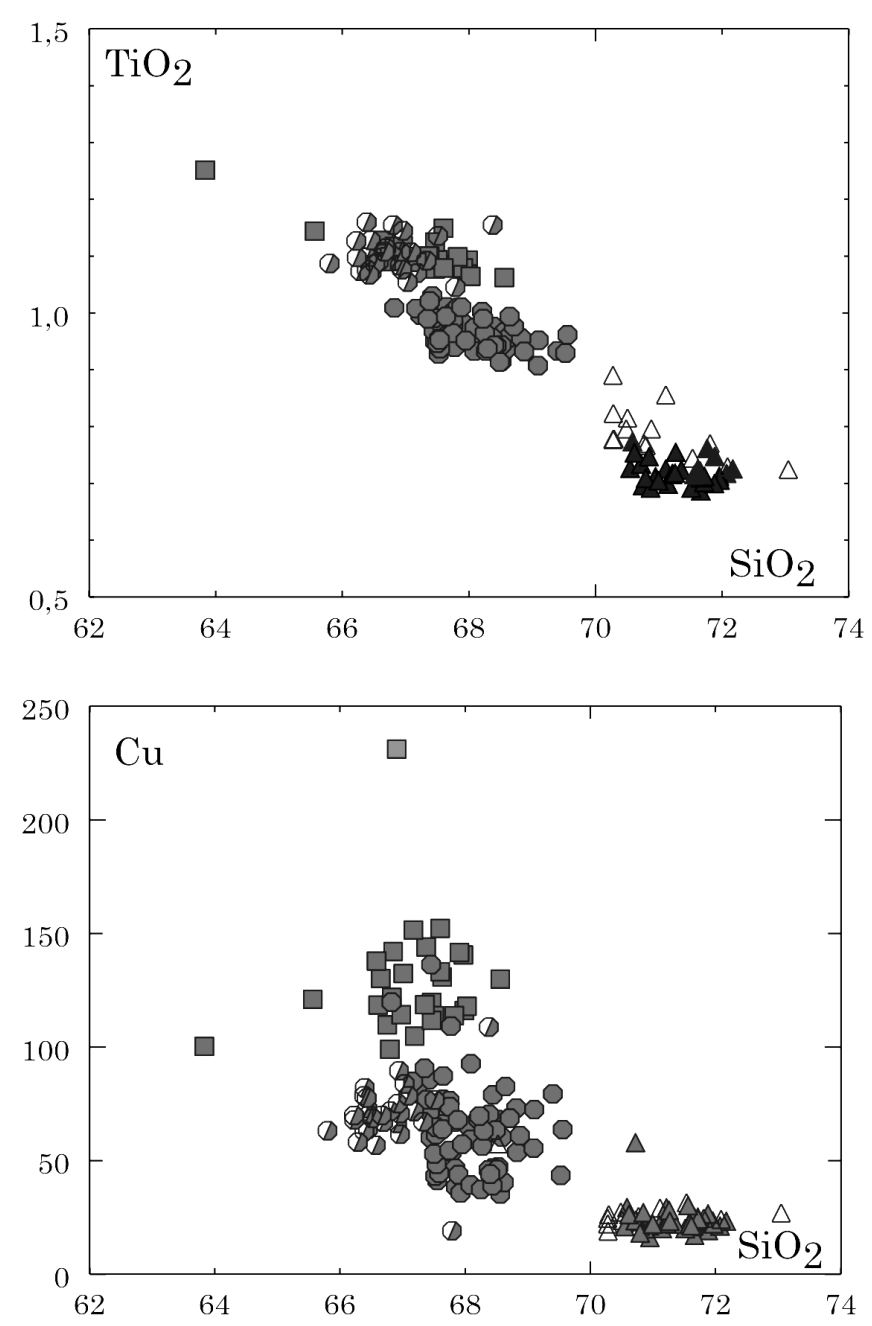

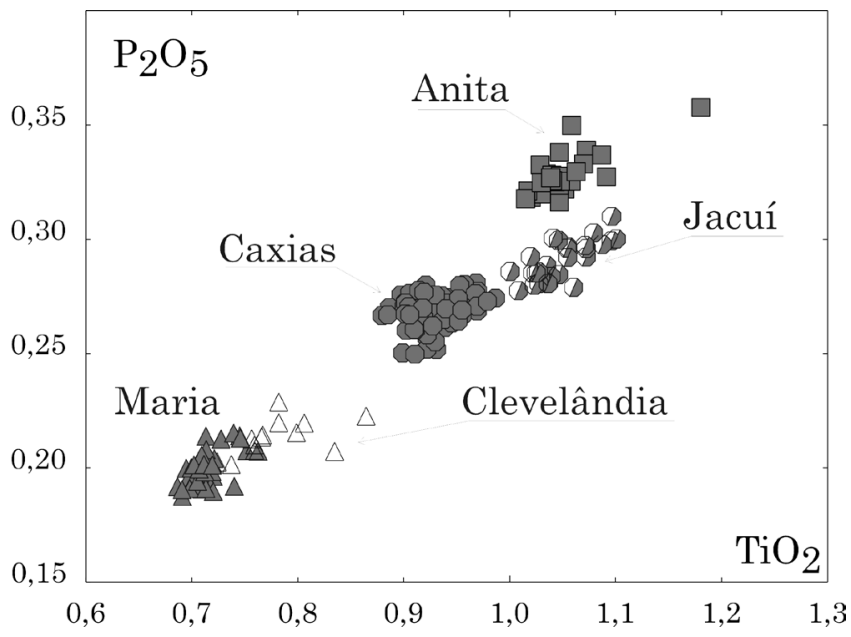

Figura 8 - Diagrama discriminante dos diferentes subgrupos de rochas do tipo Palmas.
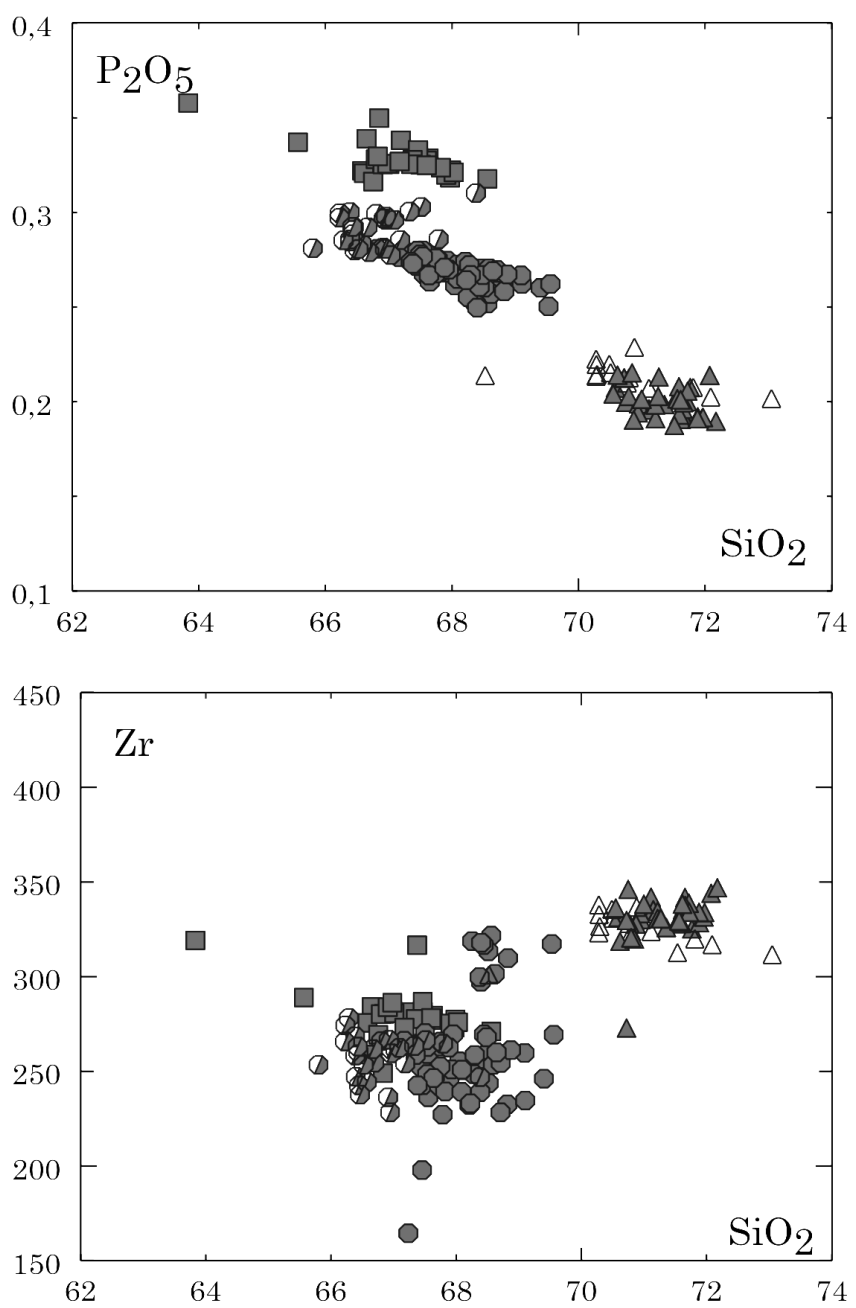

Figura 9 - Diagramas de Harker dos diferentes subgrupos de rochas do tipo Palmas. Legenda: Santa Maria (triângulos preenchidos), Clevelândia (triângulos vazios), Caxias do Sul (círculos preenchidos), Jacuí (círculos semi-preenchidos) e Anita Garibaldi (quadrados preenchidos). 
uma mesma concentração de sílica há patamares diferentes nas concentrações de $\mathrm{Cu}, \mathrm{Ti}, \mathrm{P}$ e Zr. Além disso, esses diagramas demonstram ainda que o grupo baixo em Ti é mais enriquecido em sílica $(69,56 \%$ a 70,28\%) que aquele com alto Ti, exibindo, por sua vez, um intervalo de variação de $\mathrm{SiO}_{2}$ bem maior, de $63,83 \%$ a $69,56 \%$. Esta relação se torna mais evidente quando se emprega um diagrama de variação entre dois elementos incompatíveis, como $\mathrm{Zr}$ versus $\mathrm{Rb}$ (Fig. 10), sugerindo que essas diferenças geoquímicas não são devidas a graus de evolução distintos, por exemplo, produzidos por um processo de cristalização fracionada a partir de um mesmo magma parental.

Considerando as composições químicas médias de cada um dos subgrupos de rochas do tipo ATP representadas em um diagrama de concentrações de elementos traços relativas ao manto primordial de Sun $\&$ McDonough (1989) (Fig. 11), nota-se que elas possuem um mesmo padrão de distribuição, com fortes anomalias negativas de $\mathrm{Ba}, \mathrm{Nb}, \mathrm{Sr}$ e Ti, e positiva de $\mathrm{K}$. Verifica-se também que o grupo com baixo Ti, representado pelos subgrupos Santa Maria e Clevelândia, é o que contém maiores concentrações de elementos traços incompatíveis, com exceção do Sr, P e Ti, em relação àquele com baixo Ti. Por outro lado o grupo com alto Ti apresenta uma maior relação $\mathrm{La} / \mathrm{Lu}(6,99)$ do que aquele com baixo $\mathrm{Ti}(5,88)$. Neste último grupo, as rochas do subtipo Clevelândia apresentam concentrações levemente inferiores de Th, U, Ti, Yb e Lu em comparação àquelas Santa Maria (Fig. 11).

No grupo com alto Ti, as rochas do subgrupo Anita são as mais enriquecidas em $\mathrm{Nb}, \mathrm{La}, \mathrm{Ce}, \mathrm{P}, \mathrm{Nd}, \mathrm{Zr}, \mathrm{Sm}$, Eu, Ti, Y, Yb e Lu em relação aos subtipos Jacuí e Caxias, que, por sua vez, contêm mais $\mathrm{Ba}$, Th $\mathrm{U}$ e $\mathrm{K}$ que as primeiras. Além disso, as rochas do subtipo Jacuí mostram, no geral, concentrações relativas intermediárias entre aquelas dos demais subtipos (Fig. 11). Porém, as rochas do subtipo Jacuí é o que exibe maior enriquecimento em ETR leves

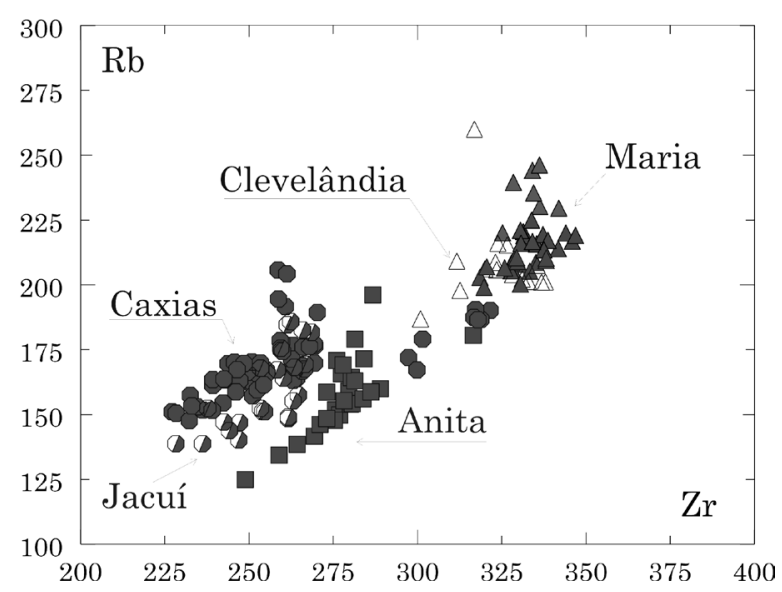

Figura 10 - Diagrama de variação (Zr vs. Rb) dos diferentes subgrupos de rochas do tipo Palmas. Legenda como na figura 9.
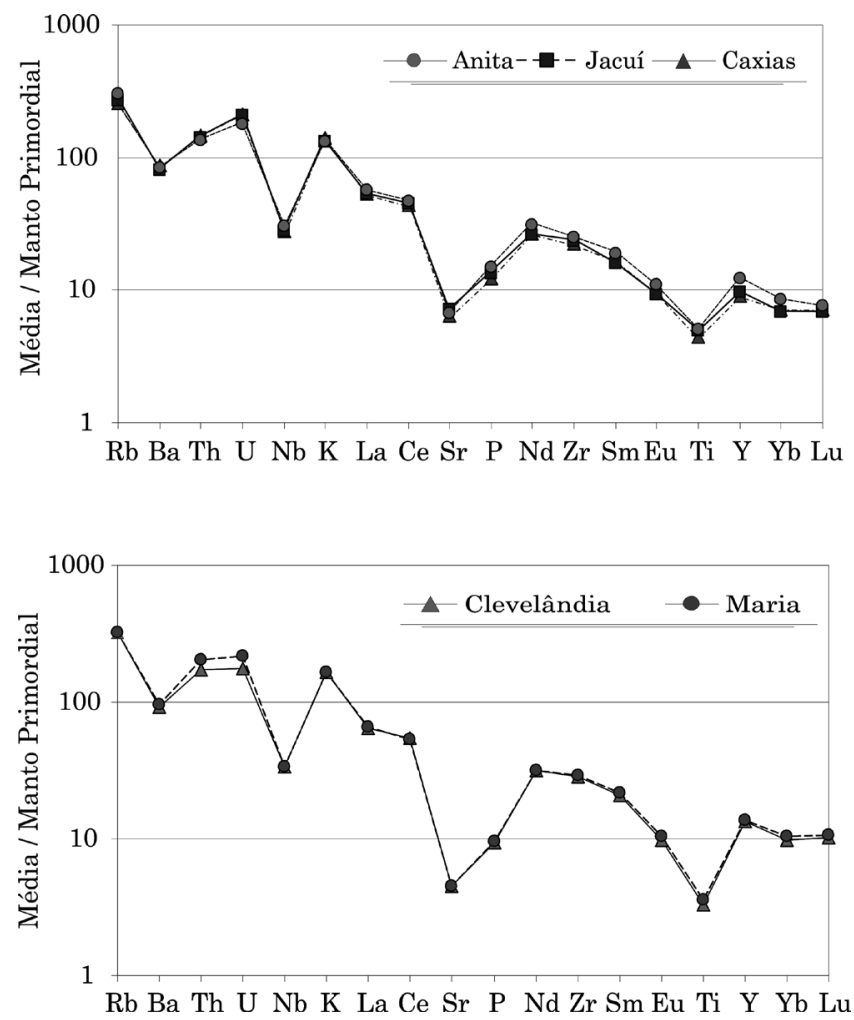

Figura 11 - Diagrama de elementos incompatíveis normalizados em relação ao manto primordial (Sun \& McDonough, 1989) das médias dos diferentes subgrupos de rochas do tipo Palmas. Legenda como na figura 9.

em relação às pesadas $(\mathrm{La} / \mathrm{Lu}=7,41)$, quando comparado aos subtipos Anita $(7,09)$ e Caxias $(7,04)$.

As rochas ácidas do tipo Chapecó Essas rochas estão distribuídas predominantemente em platôs da porção centro-norte da Bacia do Paraná, conforme mostra o mapa litoestratigráfico da figura 3 . No diagrama de variação $\mathrm{TiO}_{2}$ vs. $\mathrm{P}_{2} \mathrm{O}_{5}$ (Fig. 12), distinguem-se dois grupos principais de rochas, sendo um deles com concentrações em $\mathrm{TiO}_{2} \leq 1,29 \%$ e o outro com $\mathrm{TiO}_{2} \geq 1,47 \%$, denominados, respectivamente, de Ourinhos e Guarapuava (Garland el al., 1995). As rochas do subtipo Ourinhos sobrepõem-se diretamente aos arenitos da Formação Botucatu e acham-se distribuídas ao longo do Rio Paranapanema, cobrindo área aproximada de 432 $\mathrm{km}^{2}$ (cerca de $24 \mathrm{~km}^{3}$ ), enquanto as do tipo Guarapuava ocorrem preferencialmente próximas aos alinhamentos dos rios Uruguai e Iguaçu, formando platôs designados de: Três Pinheiros $\left(1606 \mathrm{~km}^{2}\right)$, Entre Rios $\left(401 \mathrm{~km}^{2}\right)$, Pinhão $\left(1776 \mathrm{~km}^{2}\right)$, Bituruna $\left(13 \mathrm{~km}^{2}\right)$, Mangueirinha $\left(245 \mathrm{~km}^{2}\right)$, Generoso $\left(145 \mathrm{~km}^{2}\right)$, Domingos Soares $(55$ $\mathrm{km}^{2}$ ), Abelardo Luz (309 $\left.\mathrm{km}^{2}\right)$, Xanxerê $\left(523 \mathrm{~km}^{2}\right)$, Chapecó $\left(419 \mathrm{~km}^{2}\right)$ e Goio-Ên $\left(395 \mathrm{~km}^{2}\right)$ (Fig. 3).

Entre essas duas regiões, na porção norte do Estado do Paraná, são reconhecidos dois outros platôs nas proximidades das cidades de Tamarana $\left(225 \mathrm{~km}^{2}\right)$ 


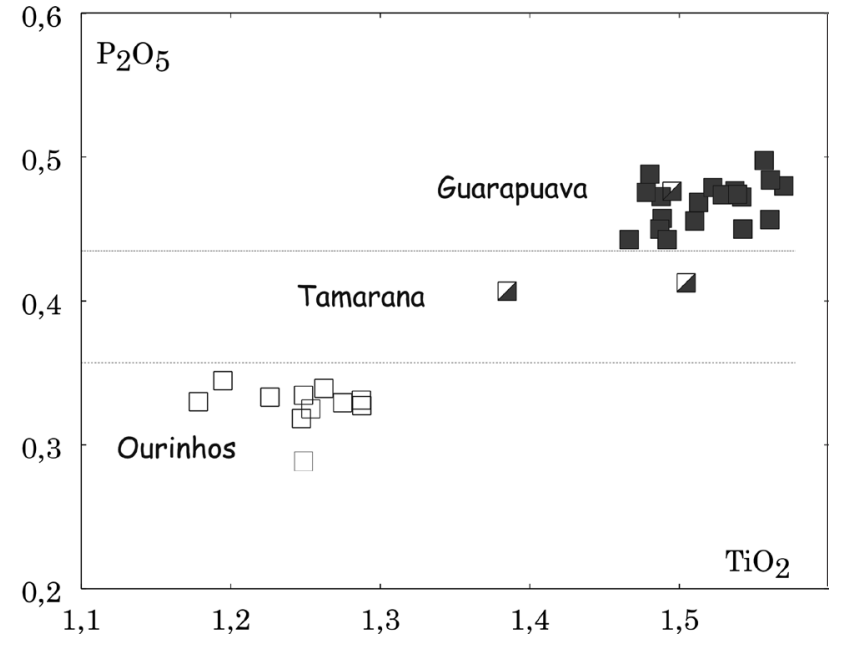

Figura 12 - Diagrama discriminante dos diferentes subgrupos de rochas do tipo Chapecó. Legenda: Ourinhos (quadrados vazios), Guarapuava (quadrados preenchidos) e Tamarana (quadrados semi-preenchidos). e Nova Santa Bárbara $\left(73 \mathrm{~km}^{2}\right)$, (Fig. 3), estando as rochas ácidas assentadas sobre os basaltos, o mesmo sucedendo com aquelas do subgrupo Guarapuava. No diagrama da figura 12 , as rochas dessas duas regiões tendem a assumir razões de $\mathrm{TiO}_{2} / \mathrm{P}_{2} \mathrm{O}_{5}$ intermediárias entre os dois grupos principais.

Quando projetadas em diagramas do tipo Harker (Fig. 13), as análises demonstram que as amostras provenientes da região de Guarapuava possuem menores concentrações em $\mathrm{SiO}_{2}(64,38$ a 66,26\%) que as da área de Ourinhos $(65,80$ a 69,12\%). Contudo, as primeiras estão mais enriquecidas em $\mathrm{Fe}_{2} \mathrm{O}_{3} \mathrm{t}, \mathrm{CaO}, \mathrm{TiO}_{2}$, $\mathrm{P}_{2} \mathrm{O}_{5}$ e $\mathrm{Zr}$ que as do tipo Ourinhos, tendendo, assim, a definir trends distintos. Por outro lado, aquelas procedentes das regiões de Tamarana e Nova Santa Bárbara, destacadas nos diagramas da figura 16 , situam-se mais próximas dos trends definidos pelas rochas da região de Guarapuava $\left(\mathrm{Al}_{2} \mathrm{O}_{3}, \mathrm{Fe}_{2} \mathrm{O}_{3}, \mathrm{CaO}\right.$ e $\left.\mathrm{TiO}_{2}\right)$, ou então, daqueles referentes às amostras da região de Ourinhos $\left(\mathrm{P}_{2} \mathrm{O}_{5}\right.$ e $\left.\mathrm{Zr}\right)$.
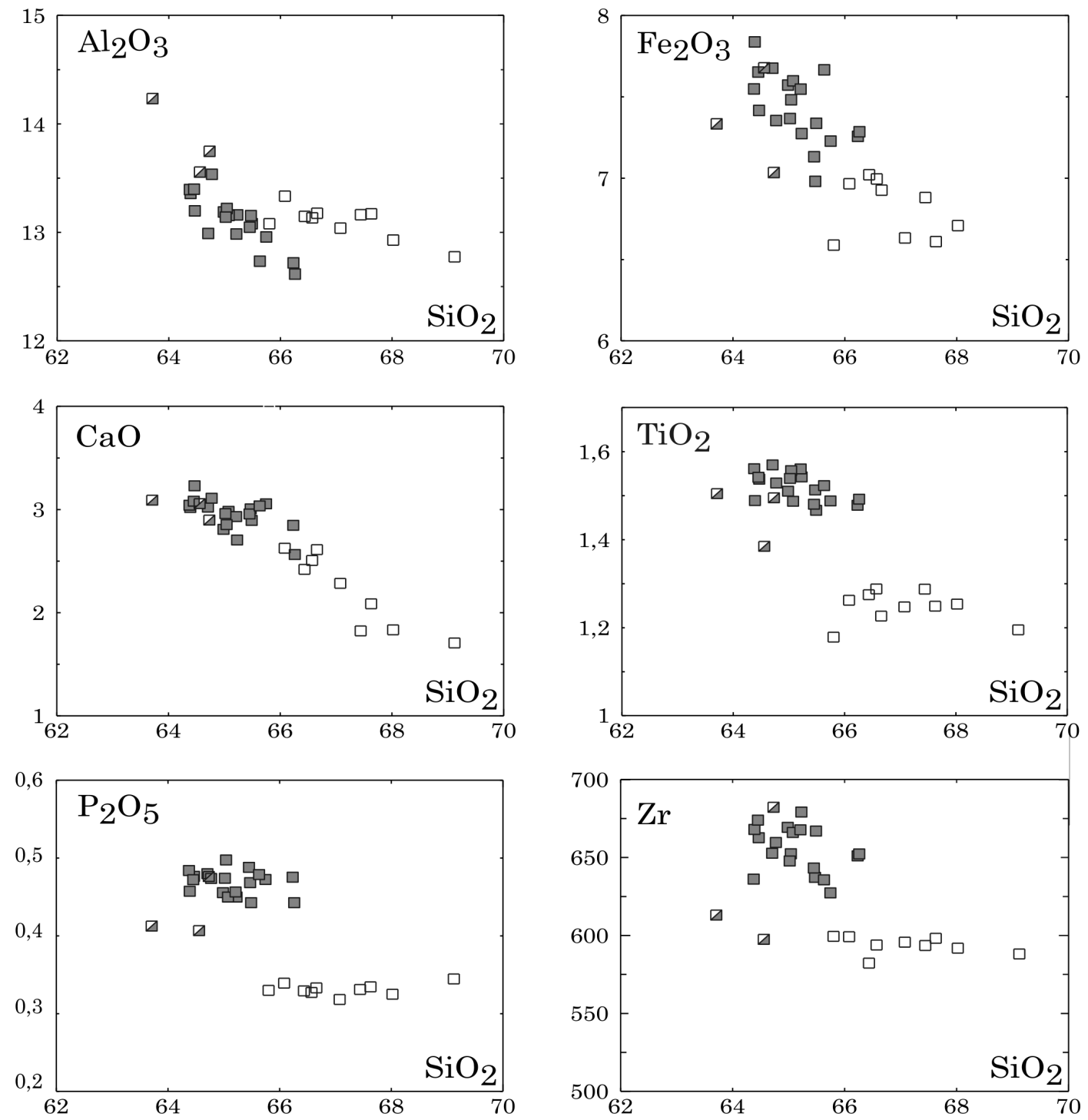

Figura 13 - Diagramas de Harker dos diferentes subgrupos de rochas do tipo Chapecó. Legenda como na figura 12. 
No diagrama normalizado para o de manto primordial (Sun \& McDonough 1989) mostrado na figura 14, vê-se que esses três tipos exibem um mesmo padrão de distribuição para os elementos traços, com fortes anomalias negativas de $\mathrm{Nb}, \mathrm{Sr}$ e Eu e positivas de $\mathrm{K}$ e Ti. Adicionalmente, nota-se que as rochas do tipo Ourinhos são mais enriquecidas em Rb (207), Ba (171), Th (148), U (140) e Y (15) comparativamente às de Guarapuava $(\mathrm{Rb}=152, \mathrm{Ba}=149, \mathrm{Th}=103, \mathrm{U}=83$, $\mathrm{Y}=14$ ), enquanto as das regiões de Tamarana e Nova Santa Bárbara possuem concentrações intermediárias de Rb (165), Ba (153), Th (114) e U (104), além de serem mais ricas nos demais elementos. Observa-se também nesse diagrama que o subgrupo Ourinhos contém maiores valores de $\mathrm{Rb} / \mathrm{Ba}(1,21)$ e $\mathrm{Sr} / \mathrm{P}(1,04)$ que o Guarapuava ( $\mathrm{Rb} / \mathrm{Ba}=1,02 ; \mathrm{Sr} / \mathrm{P}=1,04)$, sendo que este, por sua vez, apresenta taxas mais altas de $\mathrm{Th} / \mathrm{U}(1,24)$ $\mathrm{Ti} / \mathrm{Y}(4,93)$ e $\mathrm{Yb} / \mathrm{Lu}(1,09)$ em relação às primeiras $(\mathrm{Th} /$ $\mathrm{U}=1,08, \mathrm{Ti} / \mathrm{Y}=3,84, \mathrm{Yb} / \mathrm{Lu}=1,07)$. Ainda a ser mencionado que os resultados obtidos para as amostras de Tamarana e Nova Santa Bárbara são também intermediá$\operatorname{rios}(\mathrm{Rb} / \mathrm{Ba}=1,08, \mathrm{Th} / \mathrm{U}=1,10, \mathrm{Sr} / \mathrm{P}=0,88)$ entre aqueles dos subgrupos Ourinhos e Guarapuava.

Essa relação é bastante evidente quando se relacionam dois elementos fortemente incompatíveis como, por exemplo, U e Th (Fig. 15), sendo as rochas do tipo Ourinhos mais enriquecidas nesses dois elementos e as de Guarapuava mais empobrecidas, com as das regiões de Tamarana e Nova Santa Bárbara mostrando concentrações intermediárias.

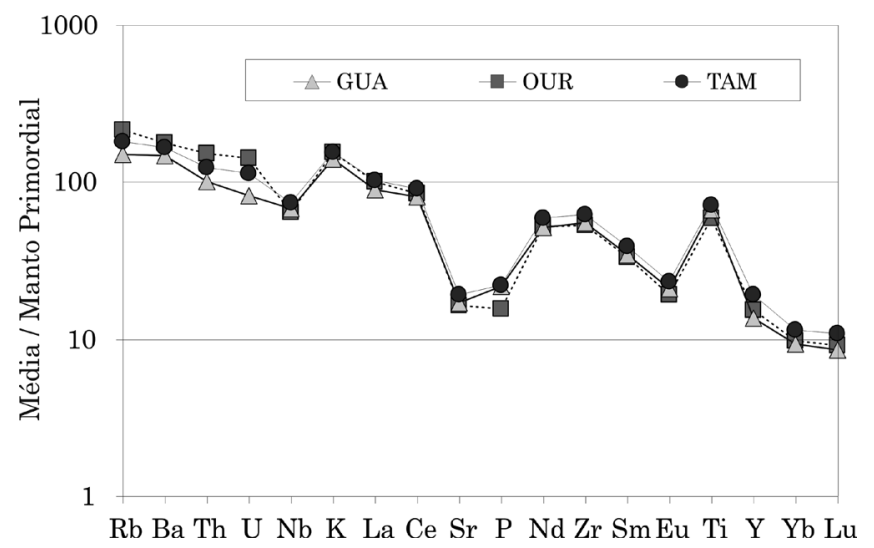

Figura 14 - Diagrama de elementos incompativeis normalizados em relação ao manto primordial (Sun \& McDonough, 1989) das composições químicas médias dos subgrupos de rochas do tipo Chapecó.

CONSIDERAÇÕES FINAIS Os novos dados geoquímicos obtidos associados ao mapeamento geológico realizado na Formação Serra Geral da Bacia do Paraná demonstraram que há uma forte relação entre o quimismo das rochas de natureza ácida com a sua distribuição

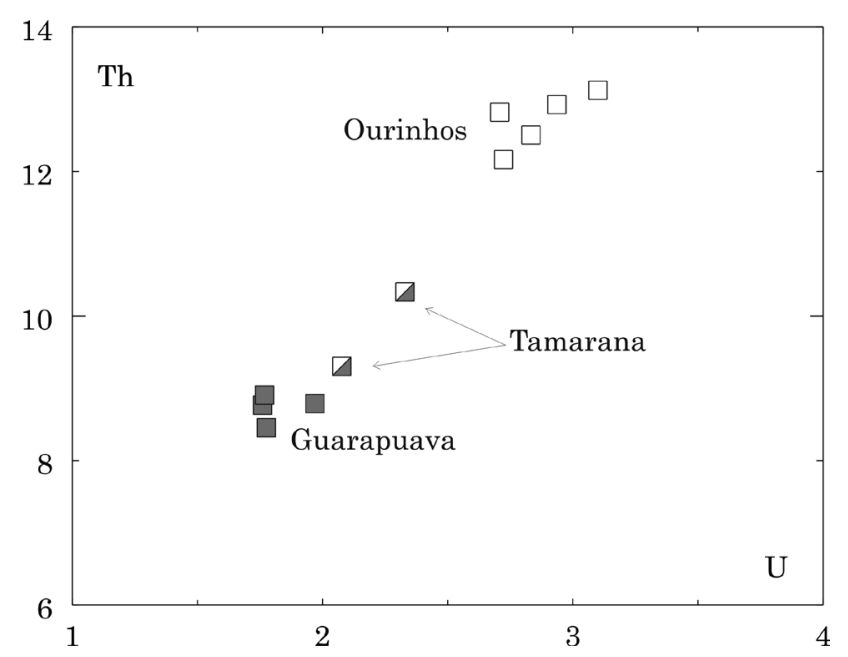

Figura 15 - Diagrama de variação (U $x$ Th) dos diferentes subgrupos de rochas do tipo Chapecó. Legenda como na figura 14.

superficial. As litologias do tipo Palmas podem ser divididas em cinco subtipos distintos, denominados de Santa Maria, Caxias do Sul, Anita Garibaldi, Clevelândia e Jacuí (Figs. 8 a 11). Esse comportamento para rochas de natureza ácida é bastante similar ao registrado na região do Etendeka, na Namíbia, onde elas foram subdivididas em dez subgrupos e as do tipo Chapecó em outros cinco por Milner el al. (1995) e Marsh el al. (2001). Além disso, é possível observar que na porção mais ao sul da Bacia do Paraná, equivalente ao norte do Estado do Rio Grande do Sul, ocorrem quatro subtipos de rochas ácidas do tipo Palmas. O exame das seções colunares desses subtipos ao longo da região (Fig. 3) permite estabelecer algumas relações geoquímico-estratigráficas, com as rochas do tipo Caxias do Sul sendo encontradas sempre nas suas porções inferiores, e as do tipo Jacuí especialmente próximas ao topo ou base das primeiras. Sobrepõem-se a elas as do tipo Anita Garibaldi e as do tipo Santa Maria, não sendo verificadas, no entanto, relações de contato entre as duas últimas. Além disso, os subgrupos Caxias do Sul, Jacuí e Santa Maria não ocorrem na porção central da Bacia do Paraná, situada entre os alinhamentos dos rios Piquiri e Uruguai, sendo ali reconhecidos apenas os subgrupos Clevelândia e Anita Garibaldi, que também não mostram relações de contato entre si e são encontrados sobrepostos diretamente aos basaltos. Esses aspectos parecem indicar que os vários tipos e subtipos de rochas vulcânicas ácidas correspondem, de fato, a diferentes magmas-tipo e que o magmatismo se deu de forma assíncrona gerando unidades de natureza diacrônica.

Agradecimentos Os autores agradecem à Fundação de Amparo à Pesquisa do Estado de São Paulo (FAPESP) e à Fundação para o Desenvolvimento da UNESP (Fundunesp) pelo suporte financeiro. Agradecem também à L.S.Marques pelas análises químicas de U e Th e ao revisor da RBG pelas valiosas sugestões ao manuscrito. 


\section{Referências}

Alberti A., Piccirillo E.M.; Bellieni G.; Civetta 1., CominChiaramonti P., Morais E.A.A. 1992. Mesozoic acid volcanics from southern Angola: petology, Sr-Nd isotope characteristics, and correlation with the acid stratoid volcanic suites of Paraná Basin (south eastern Brazil). Eur. Journ. Mineral, 4:597-604.

Bellieni G., Comin-Chiaramonti P., Marques L.S., Melfi A.J., Nardy A.J.R., Papatrechas C., Piccirillo E.M., Roisemberg A., Stolfa D. 1986. Petrogenetic Aspects of Acid and Basaltic Lavas from the Paraná Plateau (Brazil): Geological, Mineralogical and Petrochemical Relationships. Journ. of Petrol., 27(4):915-944.

Coffin M.F. \& Eldholm O. 1994. Large Igneous Provinces: crustal structure, dimensions and external consequences. Rev. Geophys., 32:1-36.

Deckart K., Féraud G., Marques L.S., Bertrand H. 1998. New time constraints on dyke swarms related to the Paraná-Etendeka magmatic province, and subsequent South Atlantic opening, southern Brazil. J. Volc. Geot. Res., 80:67-83.

De La Roche H., Leterrier P., Grandclaude P., Marchal M. 1980. A classification of volcanic and plutonic rocks using R1xR2 diagram and major element analysis. Its relationships with current nomenclature. Chem. Geol., 28:183-210.

Ernesto M., Raposo M.I.B., Marques L.S., Renne P.R., Diogo L.A., De Min A. 1999. Paleomagnetism, geochemistry and 40Ar/39Ar dating of the north-eastern Paraná Magmatic Province. Tectonic Implications. Journ. Geod., 28:321-340.

Ernesto M., Marques L.S., Piccirillo E.M., Molina E.C., Ussami N., Bellieni G. 2002. Paraná Magmatic Province - Tristan da Cunha plume system: fixed versus móbile plume, petrogenetic considerations and alternative heat sources. Journ. Volcan. Geot. Res., 118(1):15-36.

Ernst R.E., Buchan K.L., Campbell I.H. 2005. Frontiers in Large Igneous Provinces research. Lithos, 79:271-297.

Gallagher K.C., Hawkesworth C.J., Mantovani M.S.M. 1994. The denudation history of the onshore continental margin of SE Brazil inferred from apatite fission track data. J. Geophys. Res., 99:17117-18145.

Garland F., Hawkesworth C.J., Mantovani M.S.M. 1995. Description and Petrogenesis of the Paraná Rhyolites, Southern Brazil. J.Petrol., 36(5):1193-1227.

Le Bas M.J., Le Maitre R.W. Streckisen A., Zanettin B. 1986. A chemical classification of volcanic rocks based on the total alkali-silica diagram. J. Petrol., 27:745-750.

Malagutti M.I.A., Bahia Fo O., Moreno M.M.T., Nardy A.J.R. 1998. Determinação de elementos terras raras e ítrio em rochas silicáticas por ICP-AES com separação em resina trocadora de íons. Geochim. Bras., 12(1): 75-80.

Marques L.S., Alcala A.L., Santos R.N., Brenha-Ribeiro F., Hiodo F.Y. 1993. Método para determinação da concentração e composição isotópica de $\mathrm{U}$ e Th em rochas por espectrometria alfa. In: SBGf, Congresso Internacional da Sociedade Brasileira de Geofísica, 3, Resumo, p. 851853.

Marsh J.S., Ewart A., Milner S.C., Duncan A.R., Miller R.M.
2001. The Etendeka Igneous Province: magma types and their stratigraphic distribution with implications of the evolution of the Paraná-Etendeka flood basalt province. Bull. Volcan., 62:464-486.

Marzoli A., Melluso L., Morra V., Renne P.R., Sgrosso I., D’Antonio M, Morais E.A.A., Ricci G. 1999. Geochronology and Petrology of Cretaceous basaltic magmatism in the Kwanza basin (western Angola) and relationships with the Paraná - Etendeka continental flood basalt province. J. Geodyn., 28:341-356.

Melfi A.J, Piccirillo E.M., Nardy A.J.R. 1988. Geological and Magmatic Aspects of the Paraná Basin: An Introduction. In: Piccirillo A.J. \& Melfi A.J. (eds.) The Mesozoic Flood Volcanism of the Paraná Basin: Petrogenetic and and Geophysical Aspects. São Paulo, Instituto Geofísico, Astronômico e Ciências Atmosféricas, 1, Universidade de São Paulo, p. 1-13.

Milner S.C., Duncan A.R., Whittingham A.M., Ewar, A. 1995. Trans-Atlantic correlation of eruptive sequences and individual silic volcanic units within Paraná-Etendeka Igneous Province. Journ. Volcan. Geot. Res., 69:137157.

Mincato R.L., Enzweiler J., Schrank A. 2003. Novas idades ${ }^{39} \mathrm{Ar} /{ }^{40} \mathrm{Ar}$ e implicações na metalogênese dos depósitos de sulfetos magmáticos de Ni-Cu-EPG na Província Ígnea Continental do Paraná. In: SBGq, Congresso Brasileiro de Geoquímica, 9, Resumo Expandido, p. 67-92.

Misuzaki A.M.P., Petrini R., Bellieni G., Comin-Chiaramonti P., Dias J., De Min A., Piccirillo E.M. 1992. Basalt magmatism along the passive continetal margino f SE Brazil (Campos Basin). Contrib. Miner. Petrol., 111:143-160.

Nardy A.J.R., Enzweiler J., Bahia Fo O., Oliveira M.A.F., Penereiro M.A.V. 1997. Determinação de elementos maiores e menores em rochas silicáticas por espectrometria de fluorescência de raios-X: Resultados Preliminares. In: SBGq, Congresso Brasileiro de Geoquímica, 6, Resumo, p. 346-348.

Nardy A.J.R. 1996. Geologia e Petrologia do Vulcanismo Mesozóico da Região Central da Bacia do Paraná. Tese de Doutorado, Instituto de Geociências e Ciências Exatas, Universidade Estadual Paulista, 316 p.

Nardy A.J.R., Oliveira M.A.F., Betancourt R.H.S., Verdugos D.R., Machado F.B. 2002. Geologia e Estratigrafia da Formação Serra Geral. Geociências, 21(1):15-32.

Pacca I.G. \& Ernesto M. 1982. Utilização da variação paleossecular e de reversões do campo geomagnético para medida de tempo decorrido entre eventos magmáticos sucessivos. In: SBG, Congresso Brasileiro de Geologia, 32, Resumo Expandido, p. 1621-1628.

Peate D.W., Hawkesworth C., Mantovani M.M.S. 1992. Chemical sratigraphy of the Paraná lavas (S. America): classification of magma types and their spatial distribution. Bull. Volc., 55:119-139.

Peate D.W. 1997. The Paraná-Etendeka Province. In: Mahoney J.J. \& Coffin M.F. (eds.) Large igneous provinces: continental, oceanic and planetary flood volcanism. Geophys. Monogr., 100, AGU, p.217-245.

Piccirillo E.M. \& Melfi A.J.(eds.) 1988. The Mesozoic Flood 
Volcanism of the Paraná Basin: Petrogenetic and and Geophysical Aspects. São Paulo, Instituto Geofísico, Astronômico e Ciências Atmosféricas, Universidade de São Paulo, 600p.

Piccirillo E.M., Comin-Chiaramonti P., Melfi A.J., Stolfa D., Bellieni G., Marques L.S., Giaretta A., Nardy A.J.R., Pinese J.P.P., Raposo M.I.B., Roisenberg A. 1988. Petrochemistry of Continental Flood Basalt-Rhyolitic Suites and Related Intrusives from the Paraná Basin, Brazil. In: Piccirillo E.M. \&. Melfi A.J (eds.) The Mesozoic Flood Volcanism of the Paraná Basin: Petrogenetic and and Geophysical Aspects. Instituto Geofísico, Astronômico e Ciências Atmosféricas, 1, Universidade de São Paulo, São Paulo, p.107-156.

Stewart K., Turner S., Kelley S. Hawkesworth. C.J., Kirstein L., Mantovani M.S.M. 1996. 3D ${ }^{40} \mathrm{Ar}^{-39} \mathrm{Ar}$ geochronology in the Paraná flood basalt province. Earth Plan. Sc. Lett., 143:65-110.

Piccirillo E.M., Bellieni G., Cavazzini G., Comin-Chiaramonti P., Petrini R., Melfi A.J., Pinese J.P.P., Zanatadeschi P., De Min A. 1990. Lower Cretaceous tholeiitic dtke swarms from the Ponta Grossa Arch (southeast Brazil): petrology, $\mathrm{Sr}-\mathrm{Nd}$ isotopes and genetic relationships with the Paraná flood volcanics. Chem. Geol., 89:19-48.

Renne P., Ernesto M., Pacca I.G., Coe R.S., Glen J.M., Prevót M., Perrin M. 1992a: The Age of Paraná Flood Volcanism, Rifting of Gondwanaland, and the JurassicCretaceous Boundary. Science, 258:975-979.

Renne P., Ernesto M., Pacca I.G., Nardy A.J.R., Coe R.S.,
Glen J.M., Prevót M., Perrin M. 1992b. Age and Duration of Paraná Flood Vocanism in Brazil. EOS-AGU, 27:531-532.

Renne P.R., Deckart K., Ernesto M., Férraud G., Piccirllo E.M. 1996a. Age of the Ponta Grossa dike swarm (Brazil) and implications to Paraná flood volcanism. Earth Plan. Sci. Lett., 144:199-212.

Renne P.R., Glen J.M., Milner S.C., Duncan A.R. 1996b. Age of Etendeka flood volcanism and associated intrusions in southwestern África, Geology, 24:659-662.

Sun S. \& McDonough W.F. 1989. Chemical and isotopic systematics of oceanic basalts: implications for mantle composition and processes. In: Saunders A.D. \& Norry M.J. (eds.) Magmatism in the Ocean Basins. Geol. Soc. London, 1, London, p. 313-345.

Taylor S.R. \& McLennan S.M. 1981. The composition and evolution of the continental crust: rare earth element evidence from sedimentary rocks. Phil. Trans. R. Soc., A301:381-399.

Turner S., Regelous M., Kelley S., Hawksworth C., Mantovani M.M.S.1994. Magmatism and continental break-up in the South Atlantic: high precision ${ }^{40} \mathrm{Ar} /{ }^{39} \mathrm{Ar}$ geochronology. Earth Plan. Sci. Lett., 121:333-348.

Manuscrito ID 10151

Submetido em 31 de dezembro de 2007

Aceito em 21 de junho de 2008 Sistema eletrônico de submissão 